\title{
ANEXO
}

\section{El negro sensible. Drama trágico en música en un acto}

\author{
Música de Ramón Garay (1761-1823), Texto de Luciano Comella (1751-1812). \\ Partitura editada por Virginia Sánchez López ${ }^{1}$
}

\section{CRITERIOS DE EDICIÓN MUSICAL}

La única fuente conocida de El negro sensible de Ramón Garay es la partitura manuscrita conservada en Jaén, AHDJ (E:JA, según sigla RISM), 40/2. Debido a la accesibilidad al libreto literario (existen varias digitalizaciones disponibles en red) y las variantes existentes entre los distintos ejemplares manuscritos e impresos, la transcripción solo incorpora la versión musical y literaria de Garay. Para su edición se siguen los siguientes criterios:

- Las interpolaciones musicales se han numerado de manera correlativa [I-VIII]; en la fuente original no hay ningún tipo de numeración. Para cada sección se ofrece una numeración independiente de compases.

- Las articulaciones, nomenclaturas instrumentales e indicaciones de tempi y dinámica se han normalizado.

- Se han añadido ligaduras de prolongación y calderones en caso de paralelismo evidente.

- Las alteraciones accidentales solo afectan al compás en el que están, por lo que su vigencia en el compás siguiente se expresan entre paréntesis.

- A los grupos de valoración especial, indicados en el manuscrito únicamente mediante un número sobre el grupo, se les ha añadido una ligadura.

- Se ha mantenido la plica tachada en las apoyaturas, así como figura en la fuente.

- El cifrado del clave, que en el manuscrito original está sobre el pentagrama, se ha colocado debajo de este.

- Las abreviaturas rítmicas, presentes en muchos compases, se han desarrollado.

- Se incorporan las acotaciones escénicas y comentarios del manuscrito musical, en transcripción modernizada y resolviendo las abreviaturas.

1 Ver el estudio de la autora “Aportaciones al estudio del melólogo en España e Hispanoamérica: 'El negro sensible' entre dos orillas y varios contextos”, publicado en el presente número de la Revista Musical Chilena. 


\section{APARATO CRÍTICO}

Se detallan a continuación las divergencias entre la partitura manuscrita y mi transcripción.

- $\quad \mathrm{N}^{\text {o }}$ I, cc.9-10, vls. y fls.: no queda claro a qué notas afectan las indicaciones de expresión, por lo que los pianos $(p)$ se han colocado al inicio del compás y los sforzandos (sfz) a mitad.

- $\quad \mathrm{N}^{\mathrm{o}}$ III, c.3, fl. 1: se sustituye la última corchea (seguramente un error del copista) por un silencio del mismo valor, por analogía con la escritura de la fl. 2, clv. y ac.

- $\quad \mathrm{N}^{\mathrm{o}}$ III, c.13, vl. 1: el silencio de corchea del final de compás no figura en el manuscrito, intuyo que por error de copia; para cuadrar el compás se ha añadido entre paréntesis.

- $\quad \mathrm{N}^{\mathrm{o}}$ III, c.23, clv., mano derecha: el la con mordente aparece como corchea en el manuscrito; se transforma en semicorchea para cuadrar el compás.

- $\quad \mathrm{N}^{\circ}$ IV, c.22, clv., mano derecha: para cuadrar el compás se ha añadido un silencio de corchea entre paréntesis.

- $\quad \mathrm{N}^{\mathrm{o}} \mathrm{IV}, \mathrm{c.25}$, clv., mano derecha: la primera negra lleva un puntillo innecesario que se elimina en la transcripción.

- $\quad \mathrm{N}^{\mathrm{o}}$ IV, c.89, fl. 1: para cuadrar el compás se ha añadido un silencio de corchea entre paréntesis.

- $\quad \mathrm{N}^{\mathrm{O}} \mathrm{IV}$, c.94, clv., mano izquierda: para cuadrar el compás se ha añadido un silencio de corchea entre paréntesis.

- $\quad \mathrm{N}^{\circ} \mathrm{V}, \mathrm{c} .21$, clv., mano derecha: una mancha impide ver con claridad la primera nota, que se ha interpretado como un acorde Do-Mi por coherencia con el material melódico de vls. y fls.

- $\quad \mathrm{N}^{\circ}$ VIII, c.16, vls., fls. y clv, mano derecha: el Si final de compás, que por armadura debe ser bemol, se cambia a becuadro como sensible de Do. 


\section{EL NEGRO SENSIBLE}

Drama trágico en música en un acto Para cl Marqués del Cerro

Fuente: EJA: 40/2

Edición: Virginia Sánchez López
Texto: Luciano Comella (1751-1812)

Música: Ramón Garay (1761-1823)

Catul se abrava con el niño Despacio Amoroso
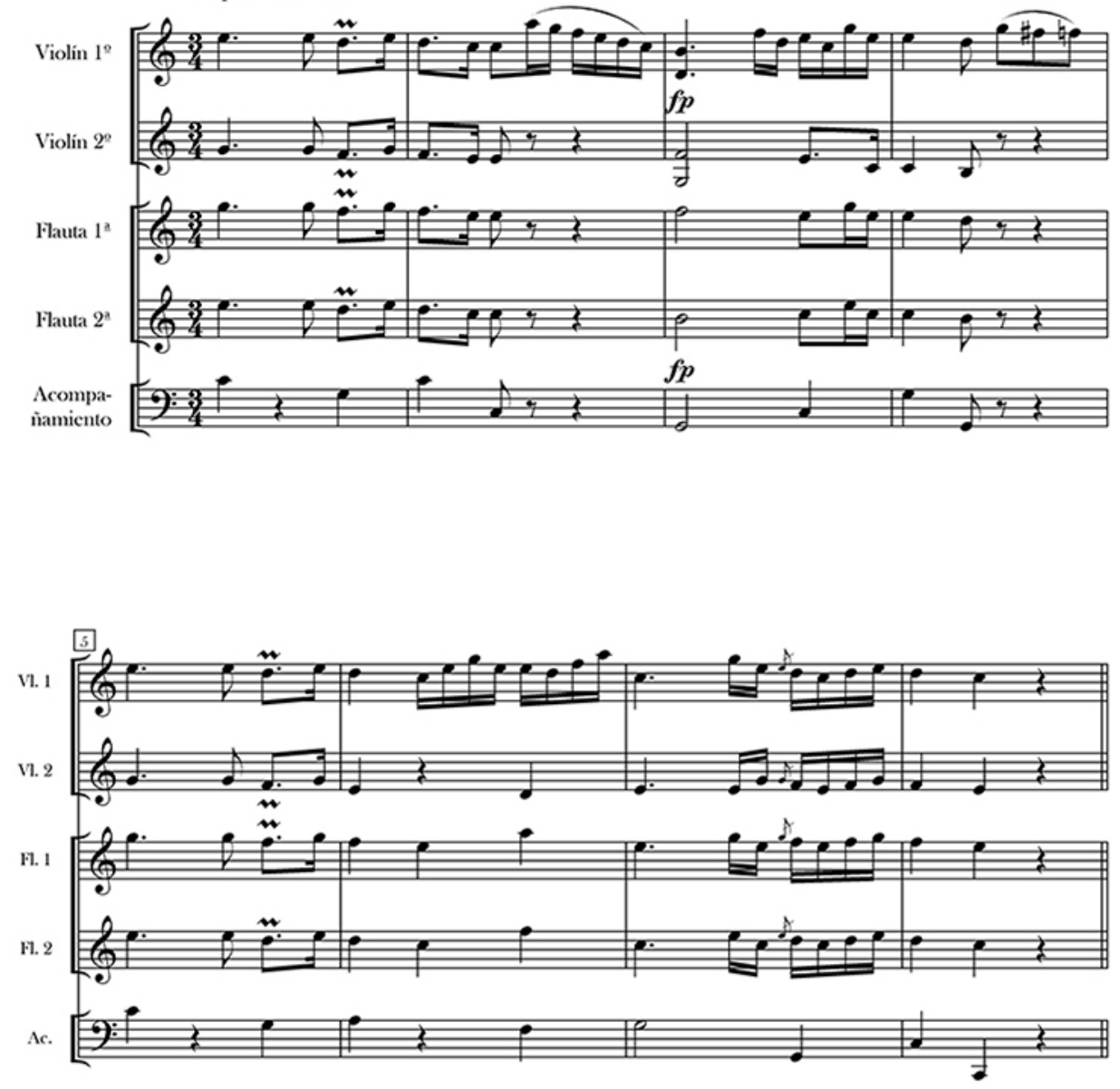

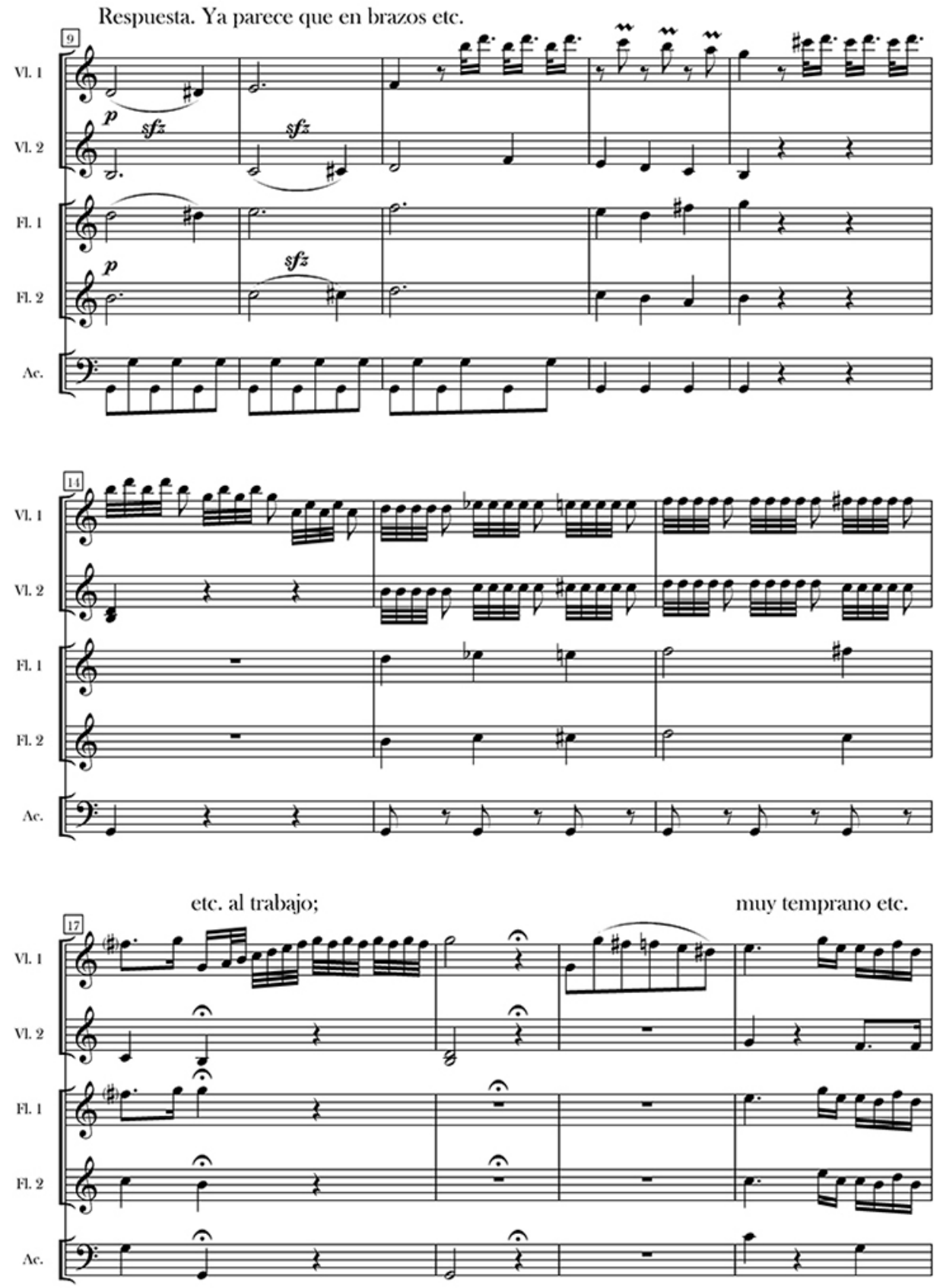

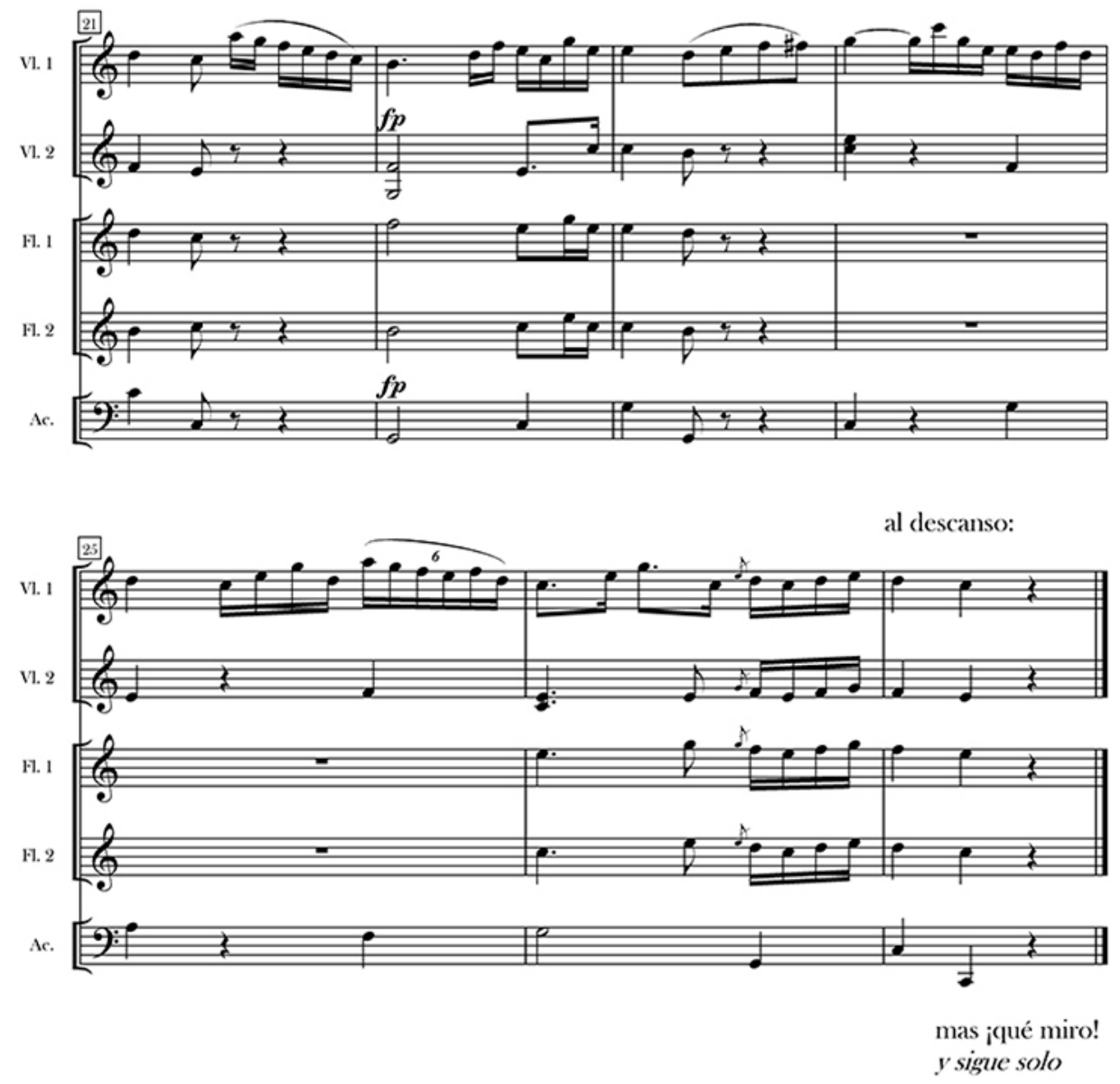

Esta escena se representará como va anotada, y si acaso le faltare algo que hablar a Catul cuando llegue al calderón (que lo deberá medir de modo que le falte), callará la música, y luego que concluya, dirá el violín primero el compás de música que tiene a solo, y volverá a representar los dos versos siguientes muy despacio alargando, entreteniéndose con el niño. 
Catul se estrecha tiernamente con su hijo Despacio
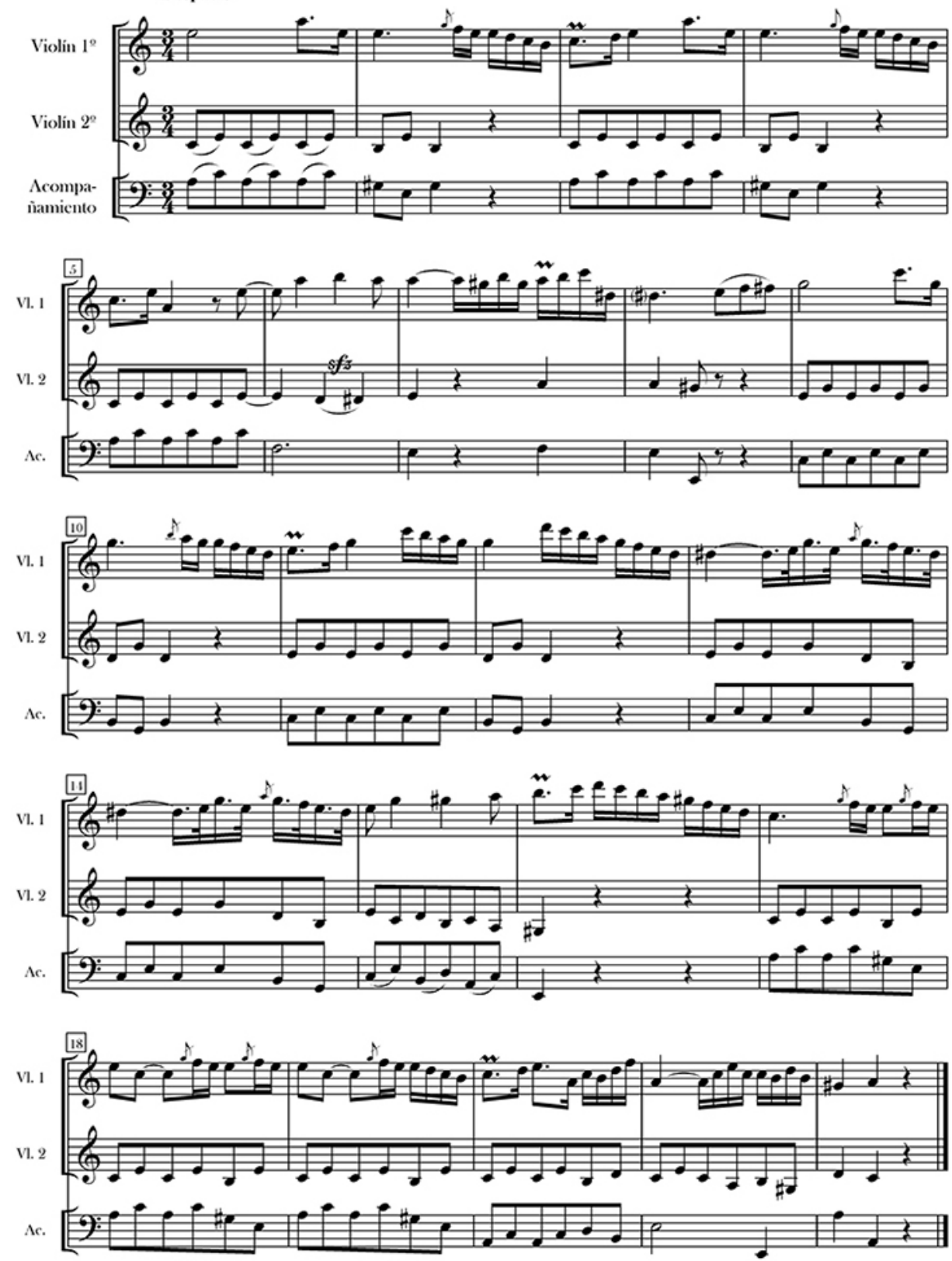
Toda esta música se ejecutará entre tanto que Catul se estrecha tiernamente con su hijo, besa los pies a Jacobo, y se va.

III
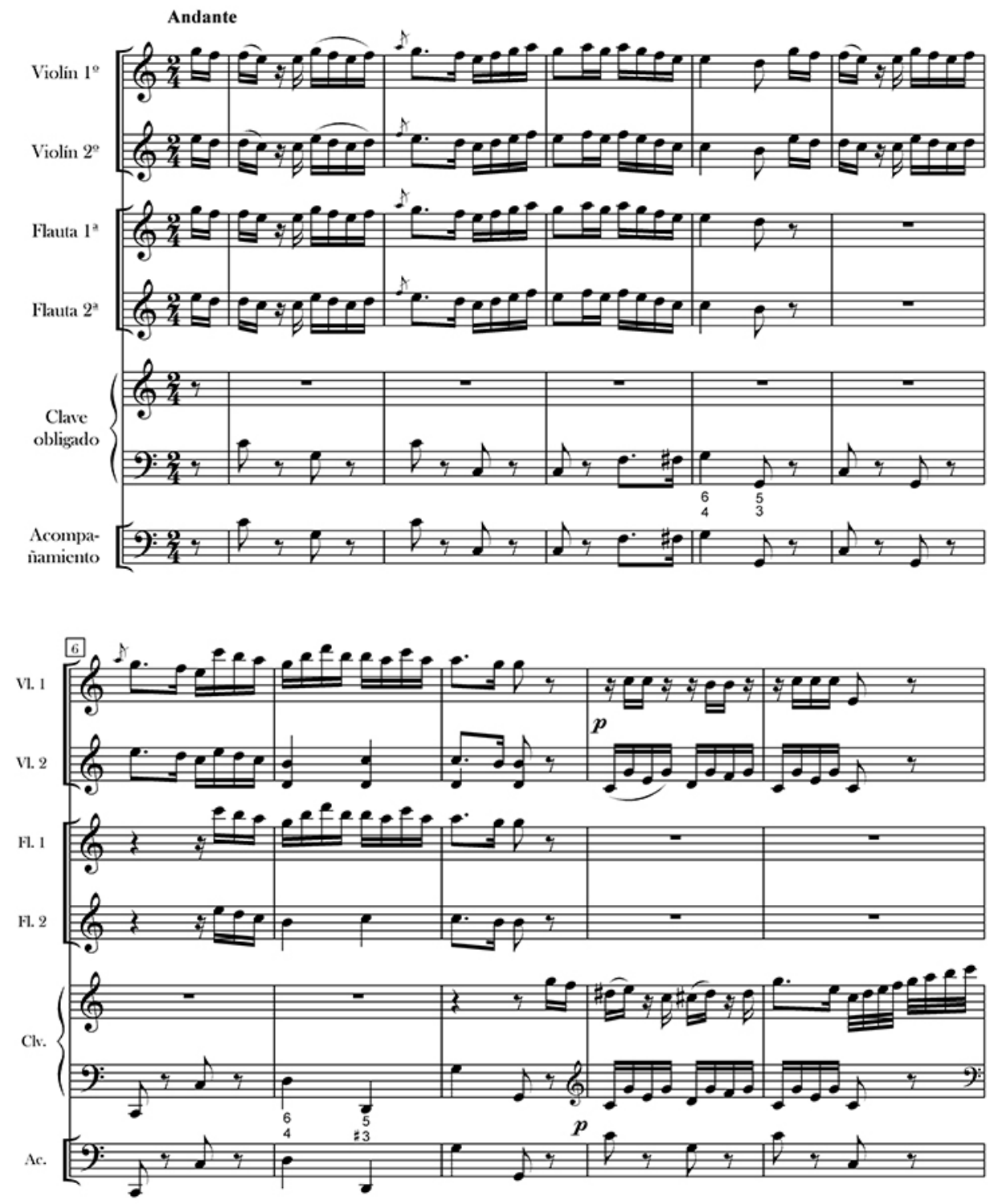

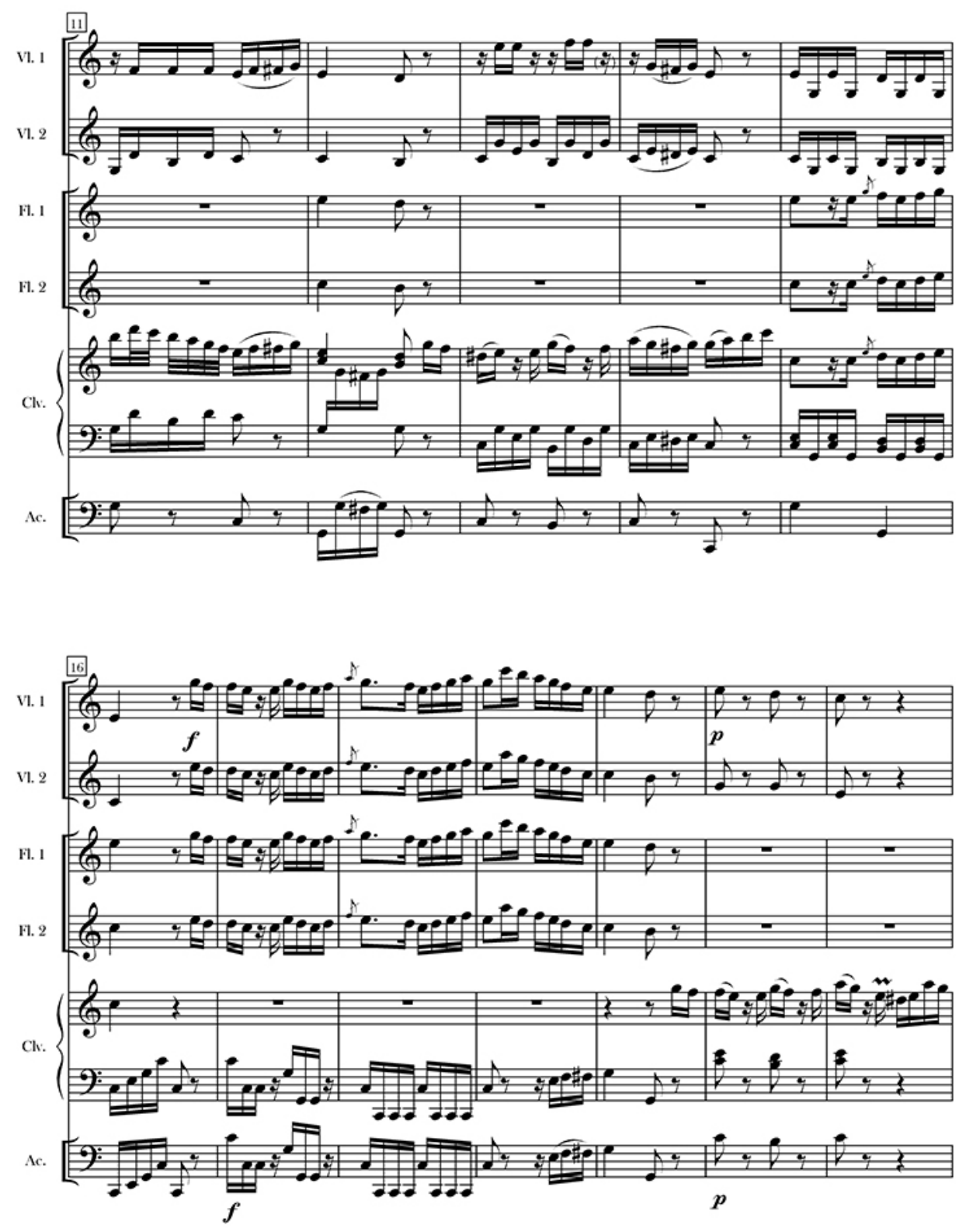

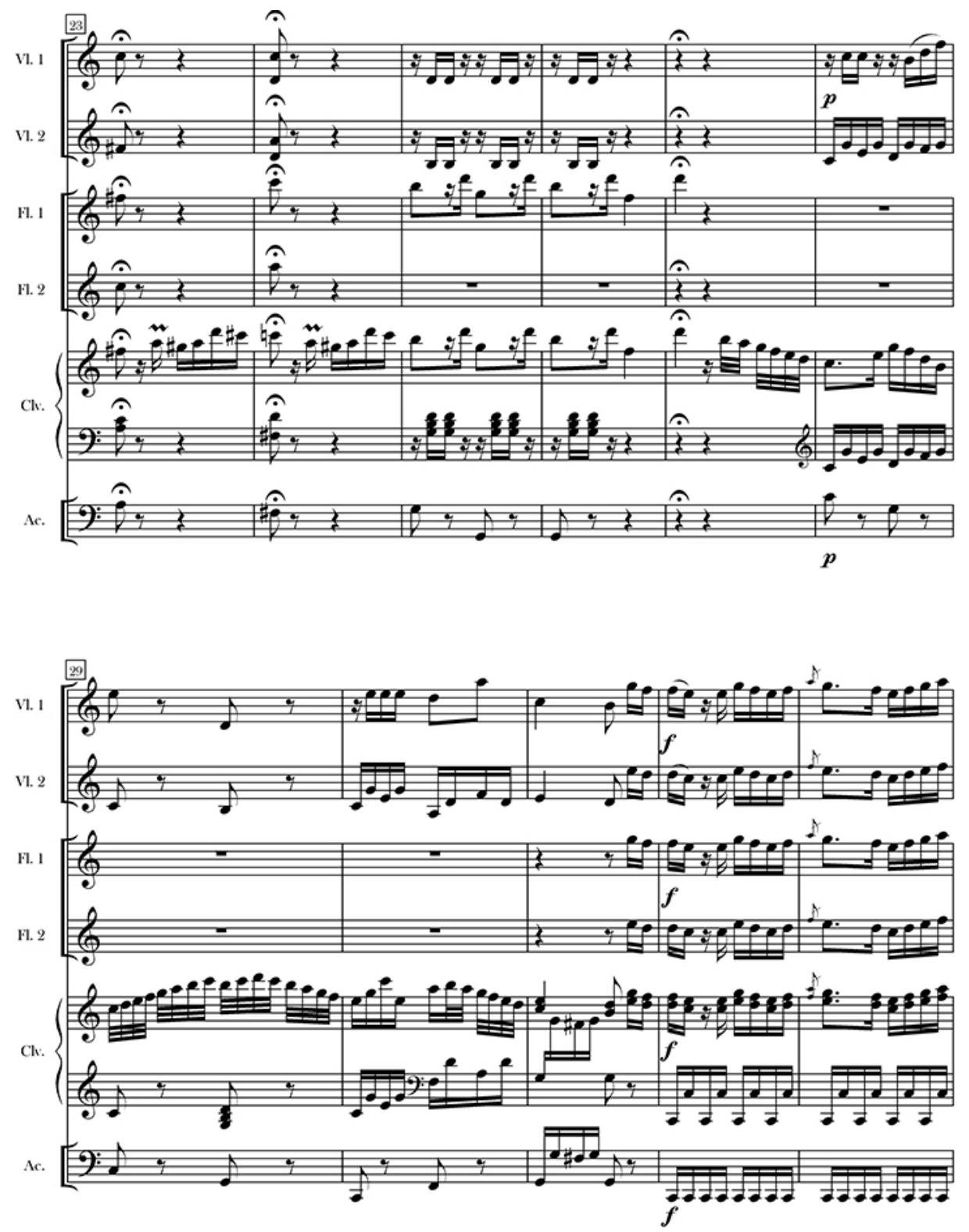


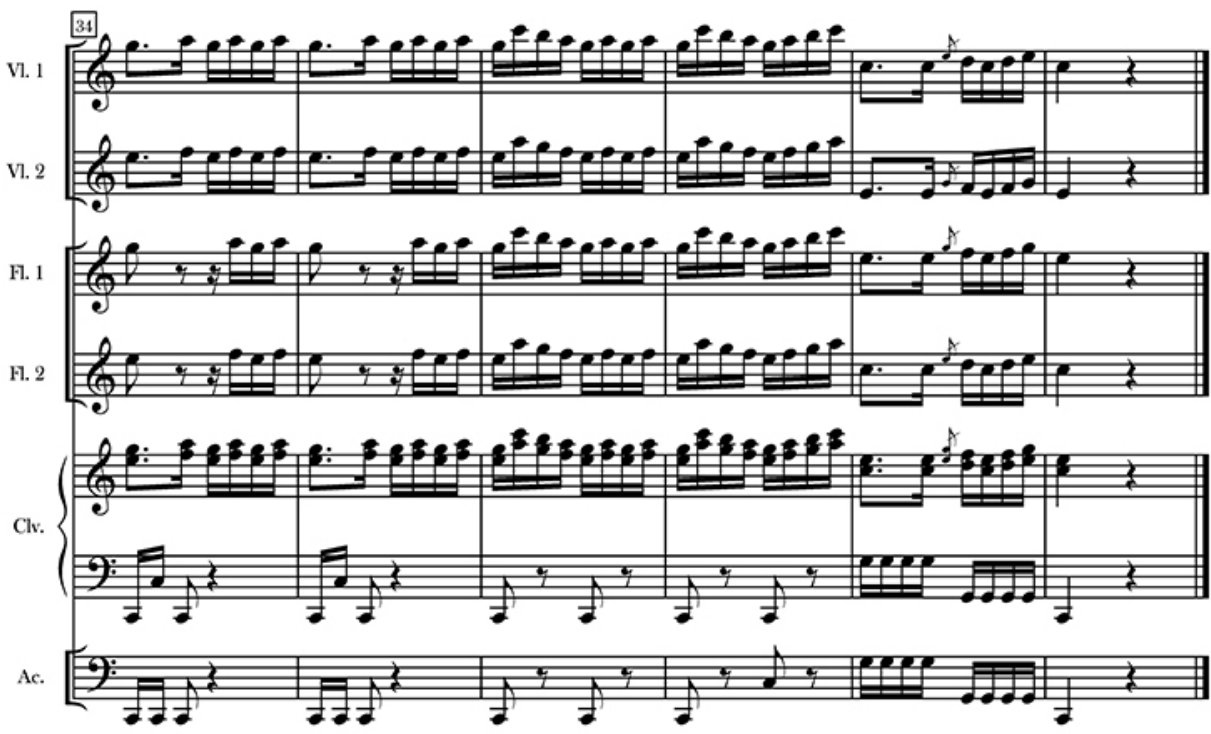

Toda esta escena se ejecutará sin que haya representación en nada de ella.

Los negros se postran a Doña Martina Andante Moderato

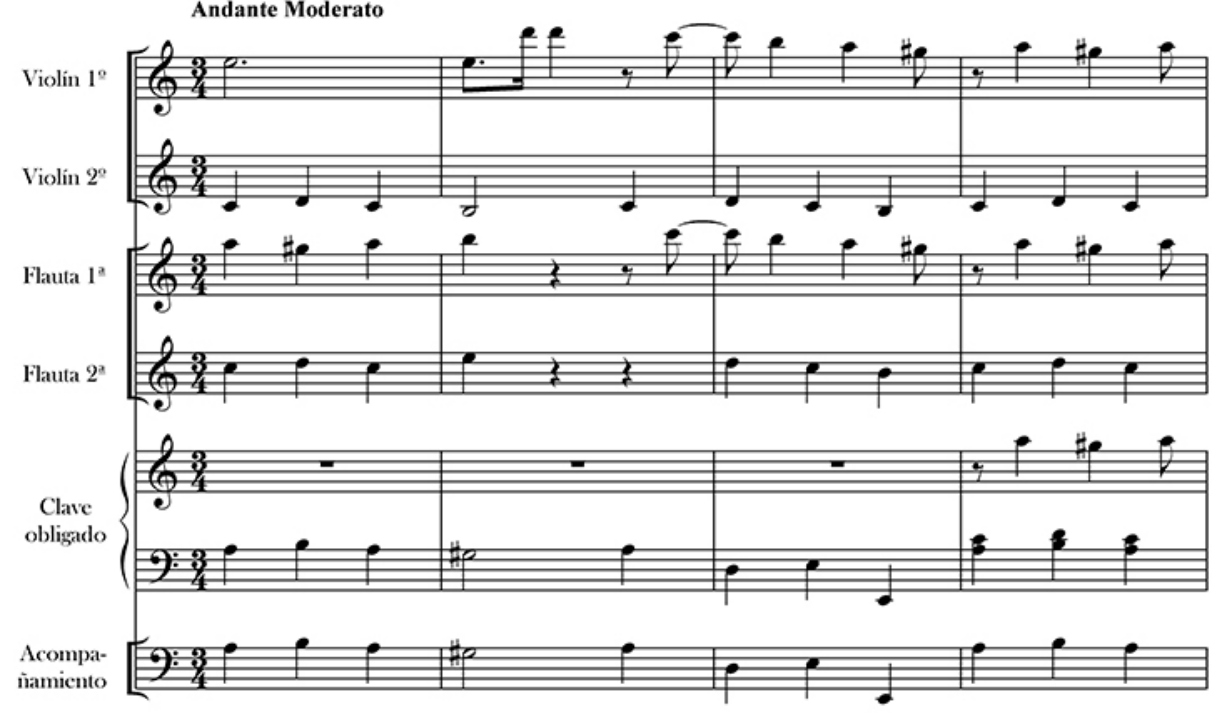



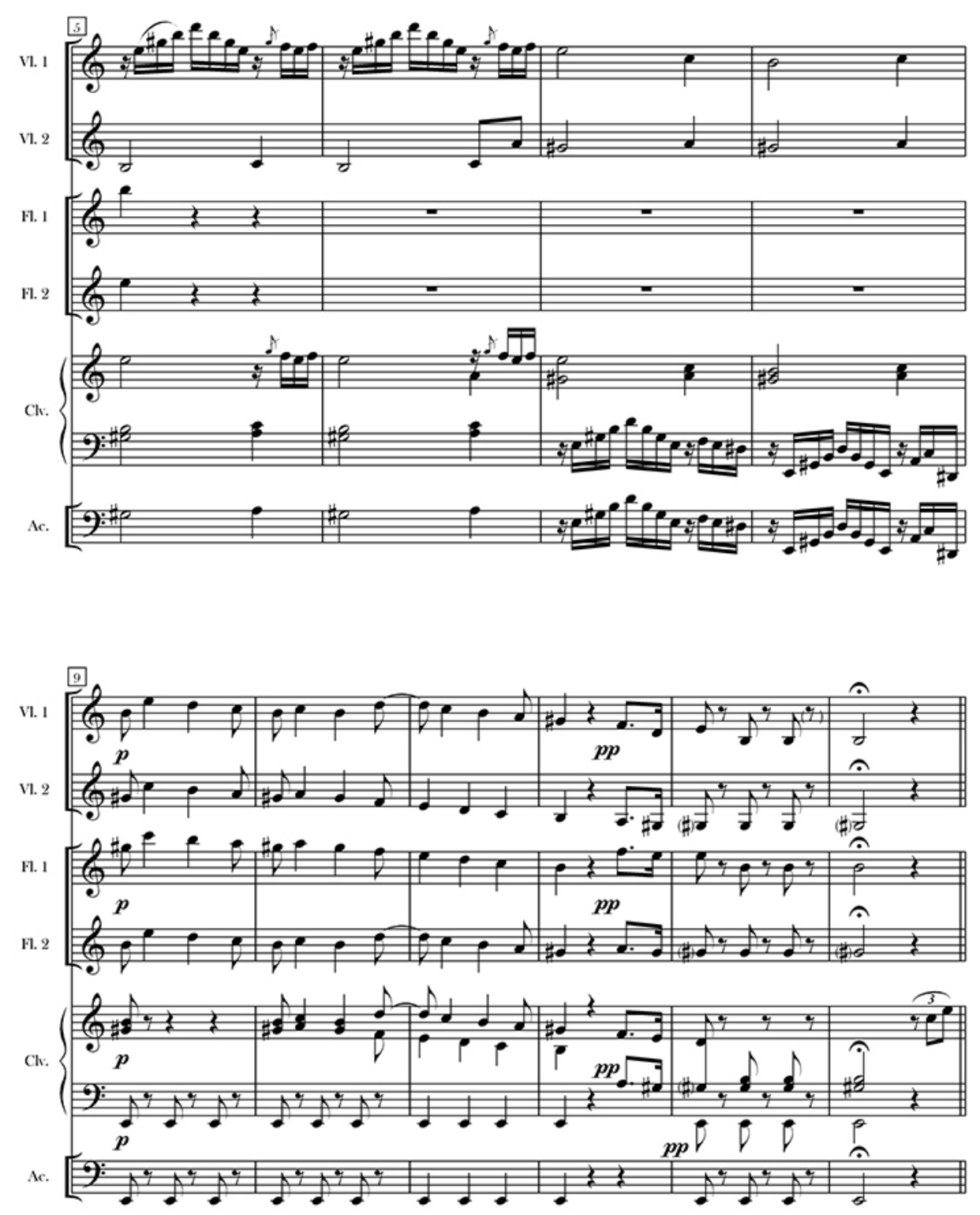
Doña Martina los consuela, alegra y les reparte dinero Allegro
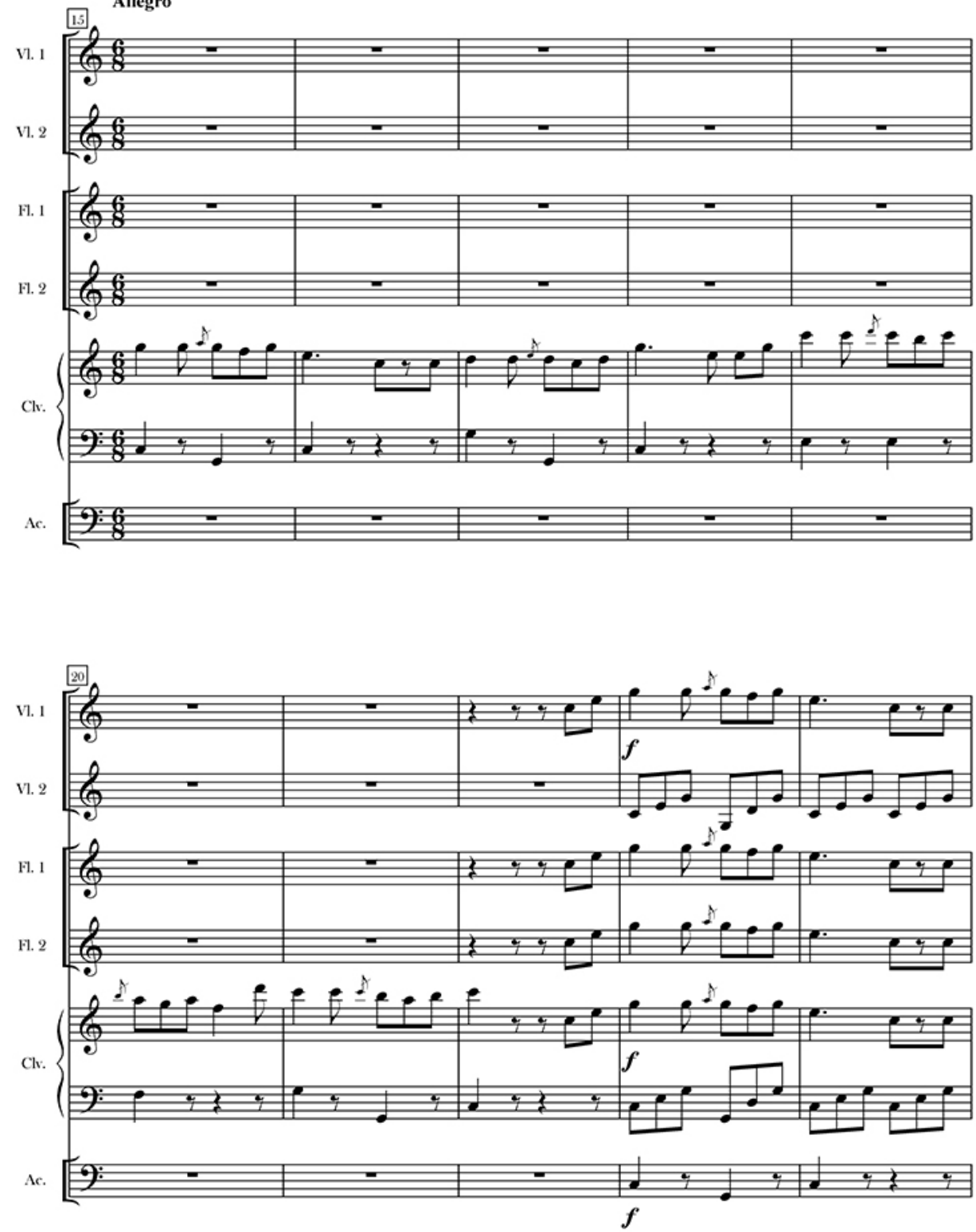

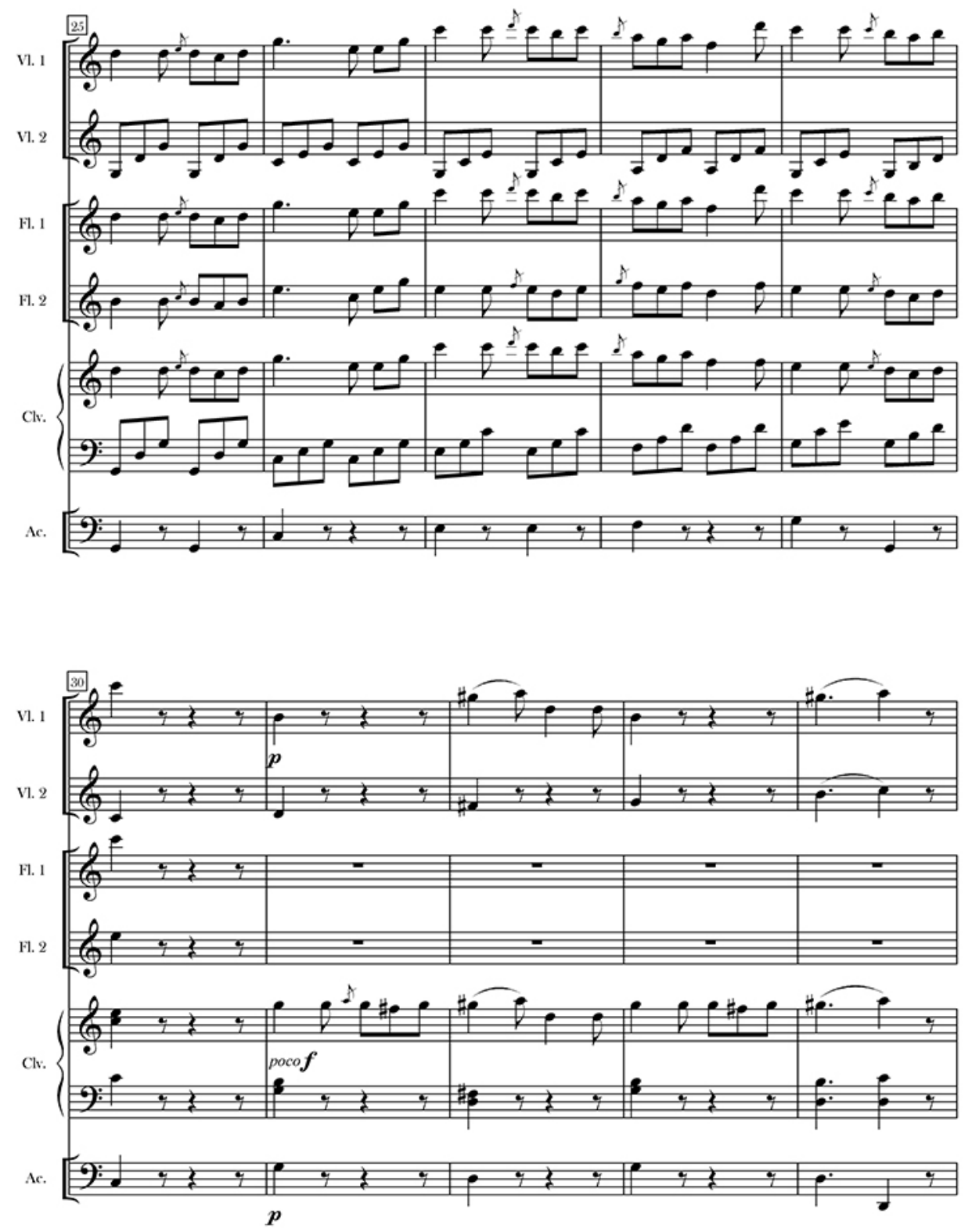

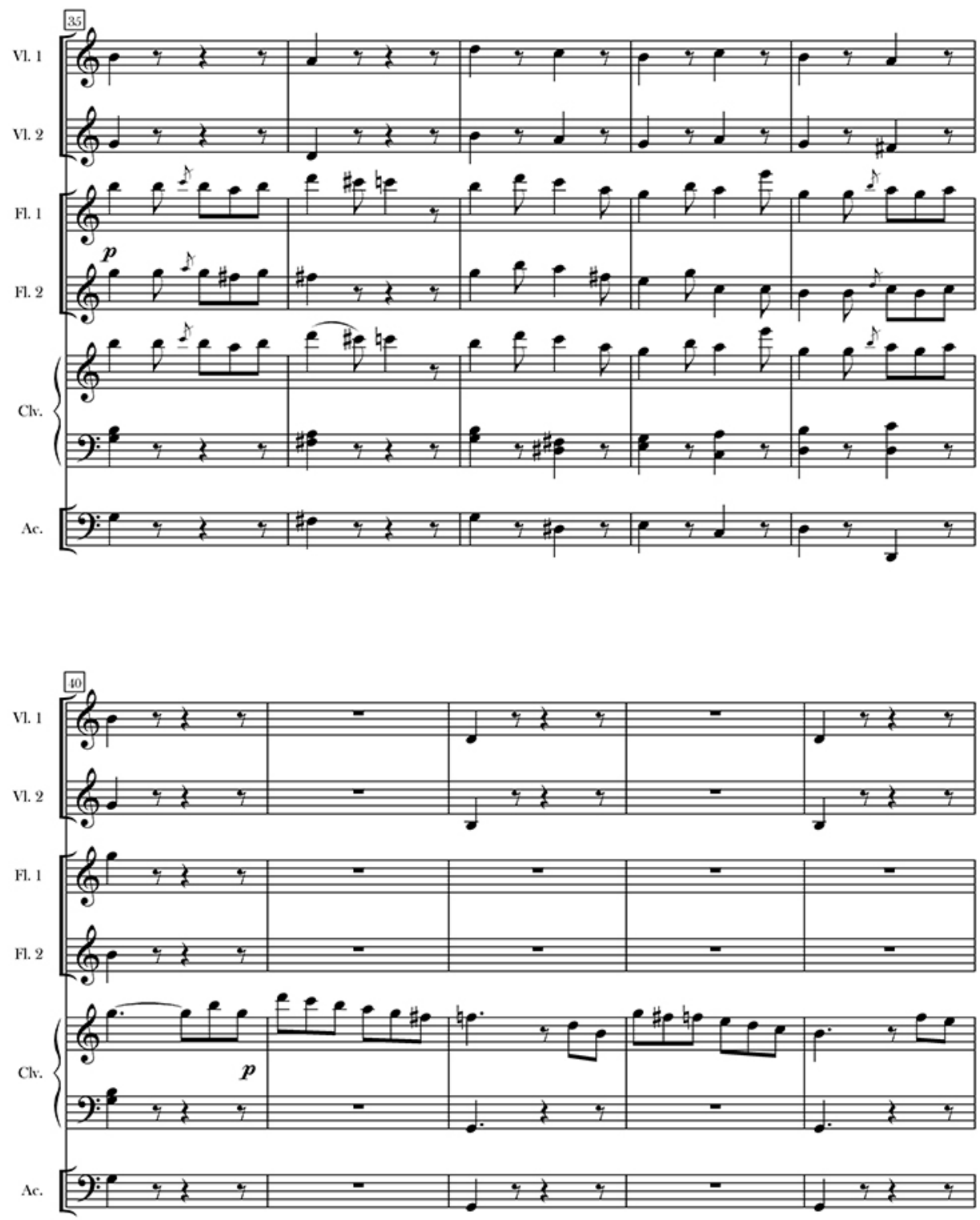

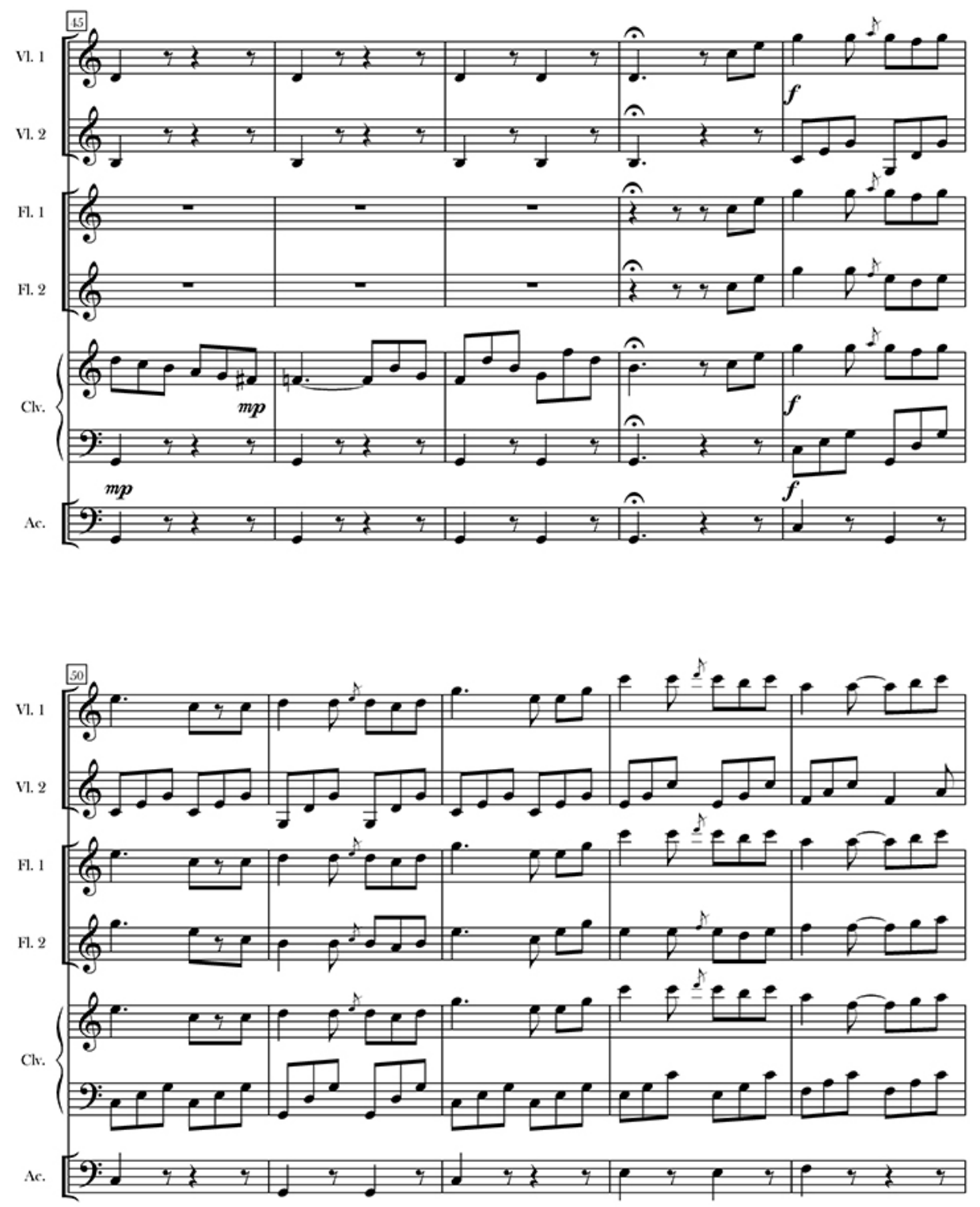
Distracción de las criadas
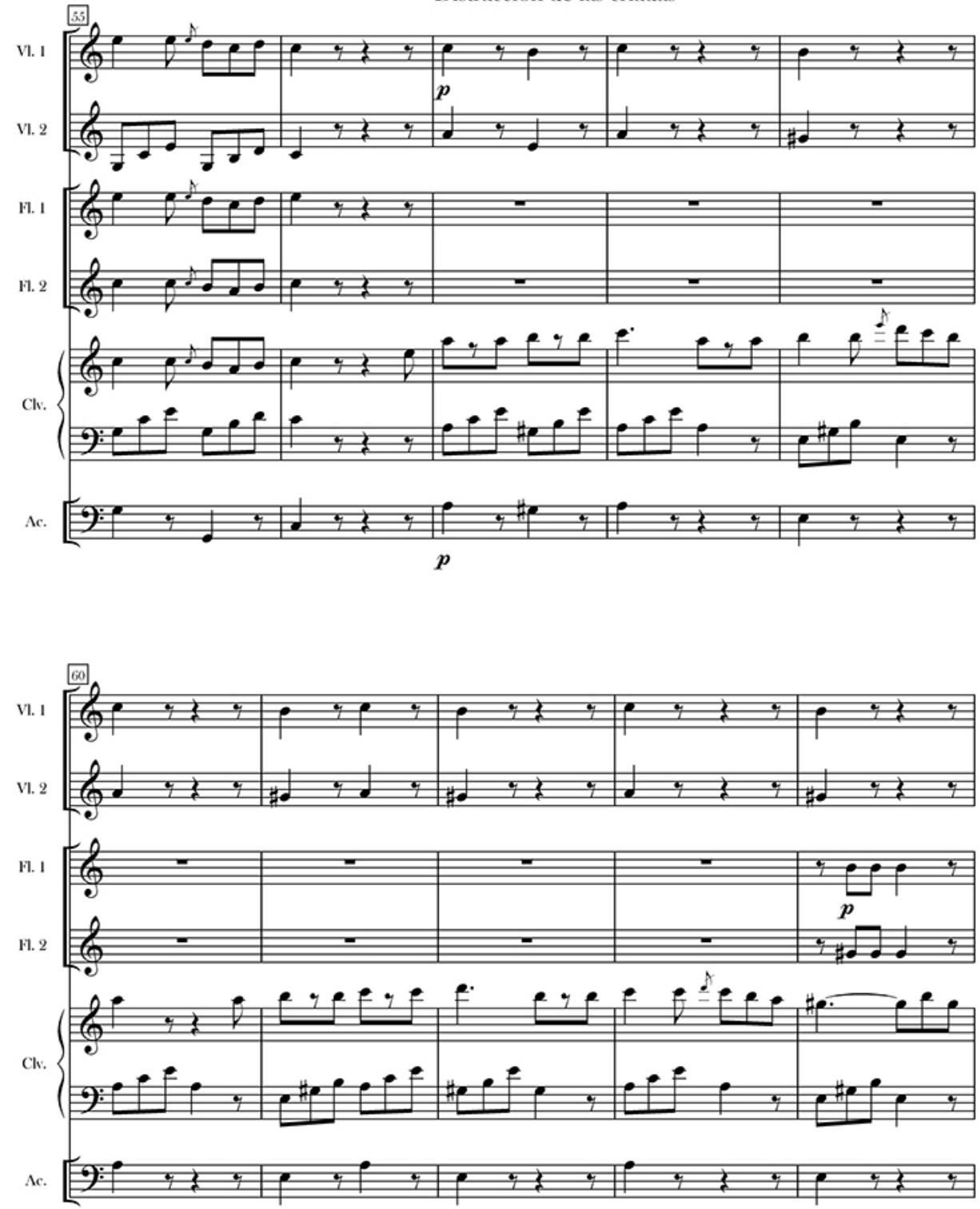

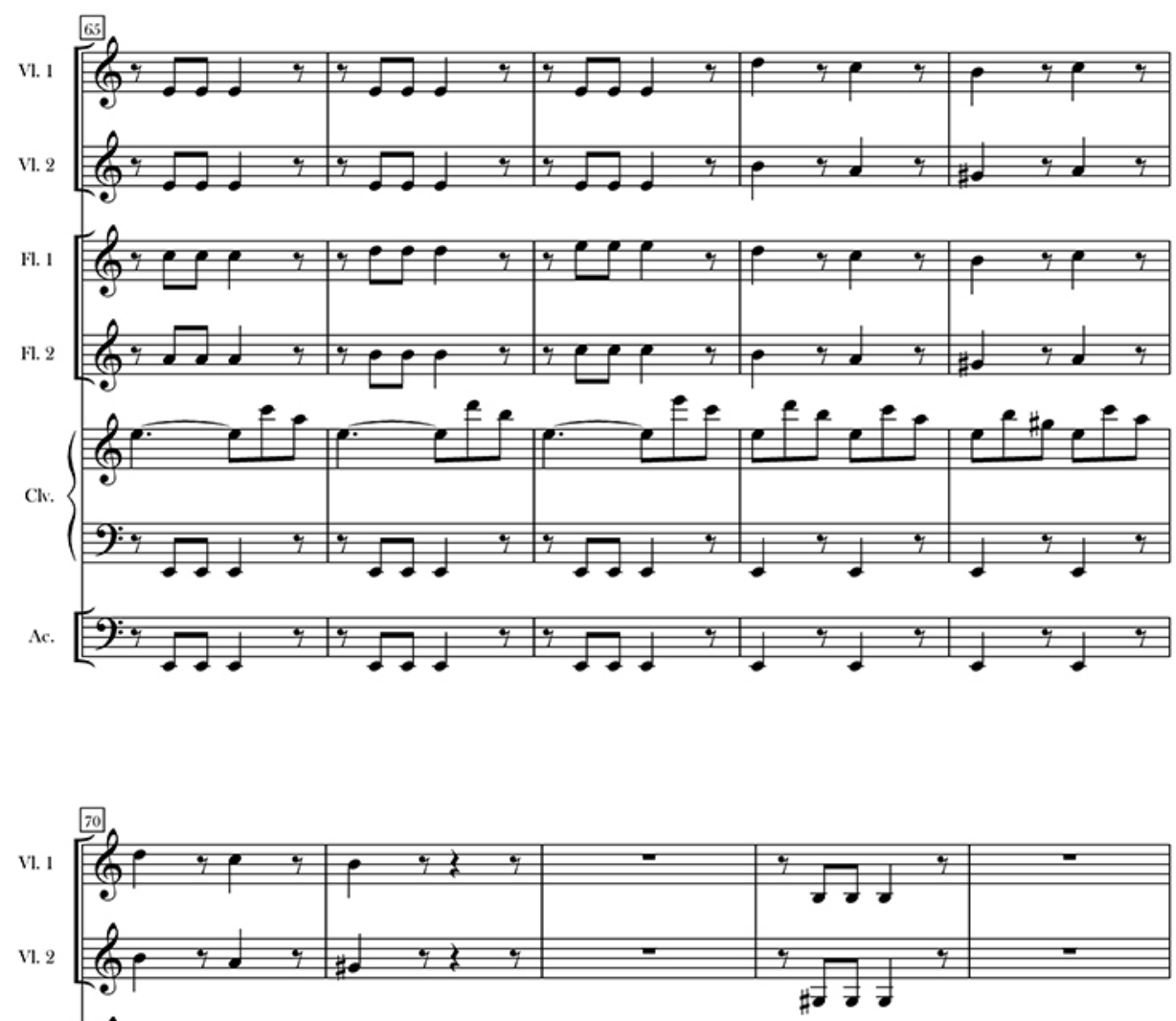

F1. 1

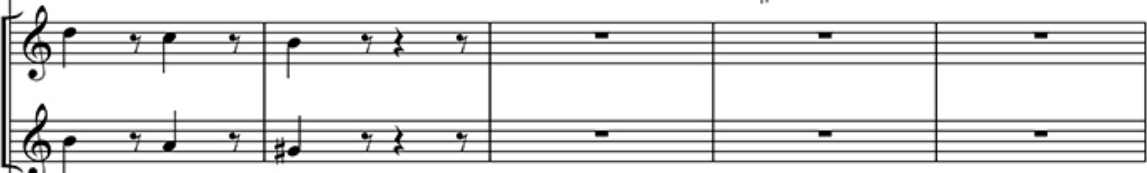

Cls.

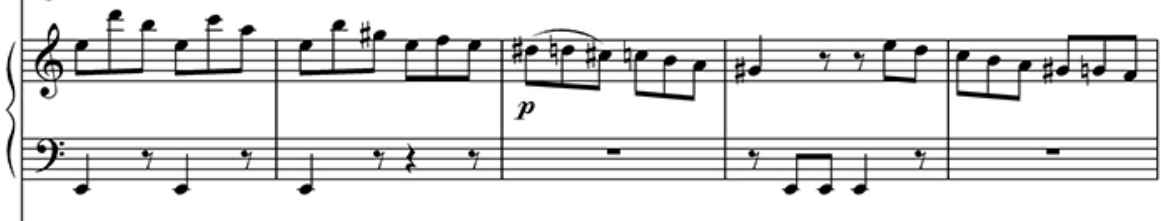

Ac.

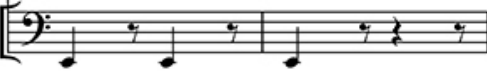

12529 
Regalo de las frutas
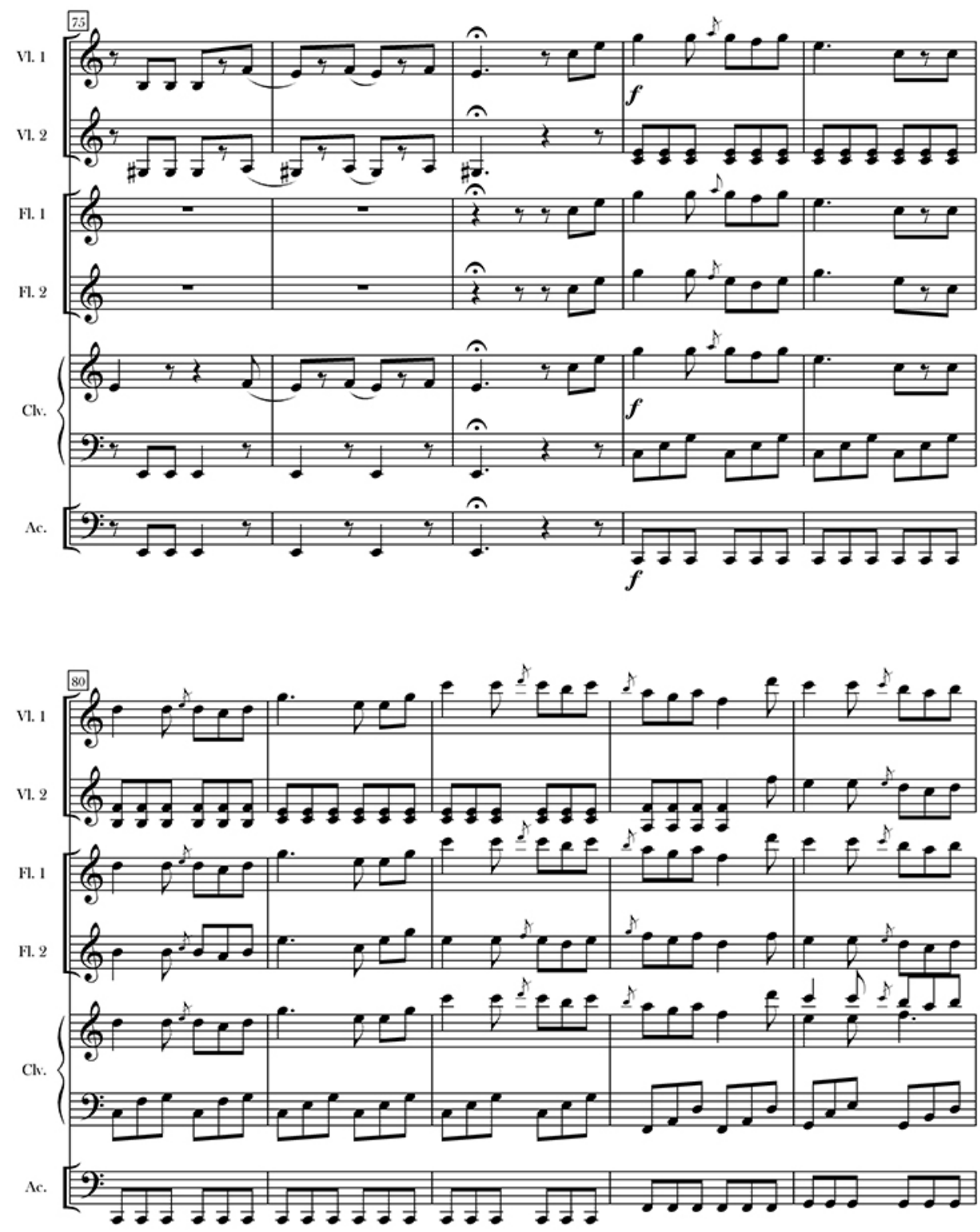

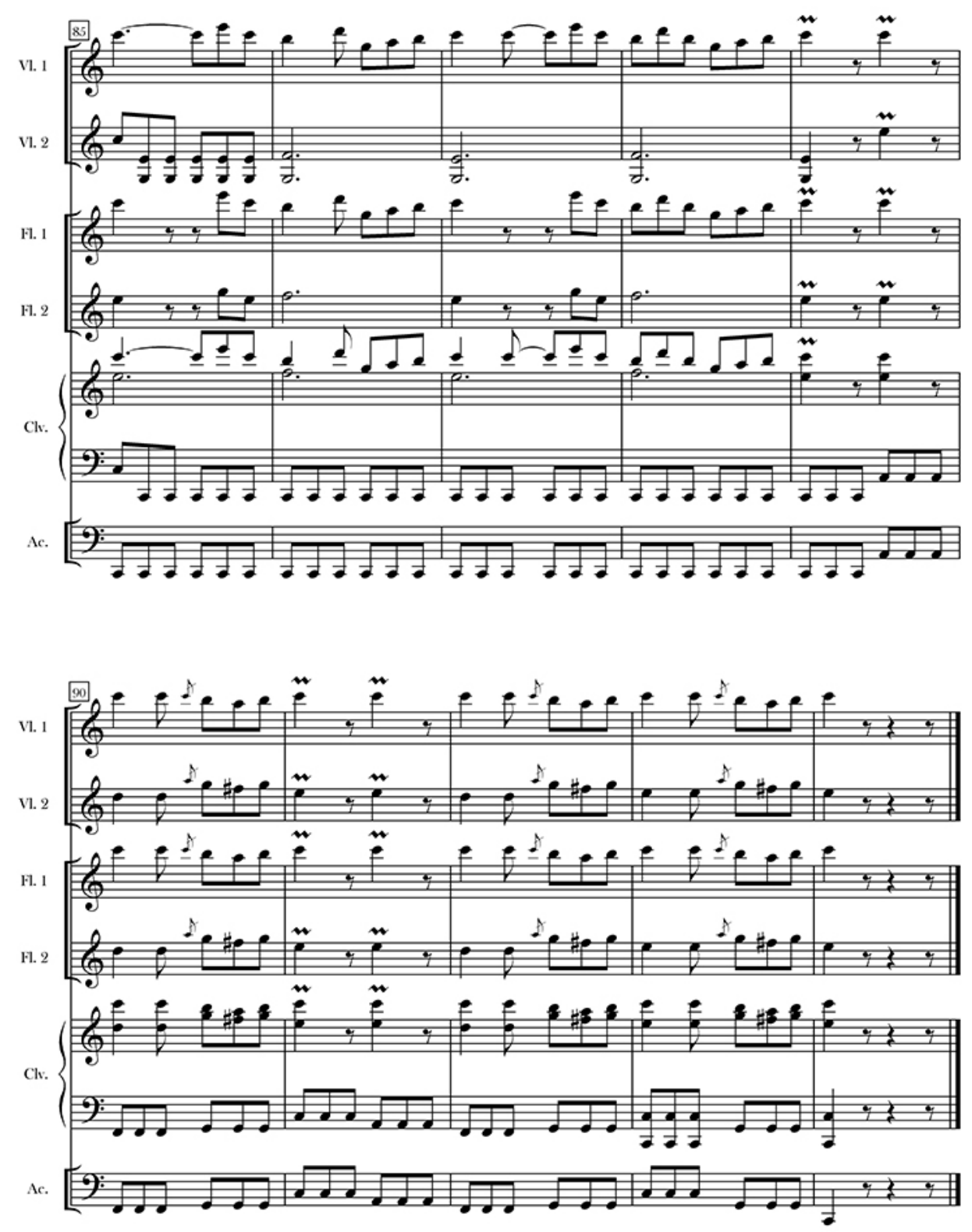

Esta es una de las escenas más interesantes y la que sigue también hará buen efecto. 
Catul sale con un haz de cañas al hombro etc.

Despacio

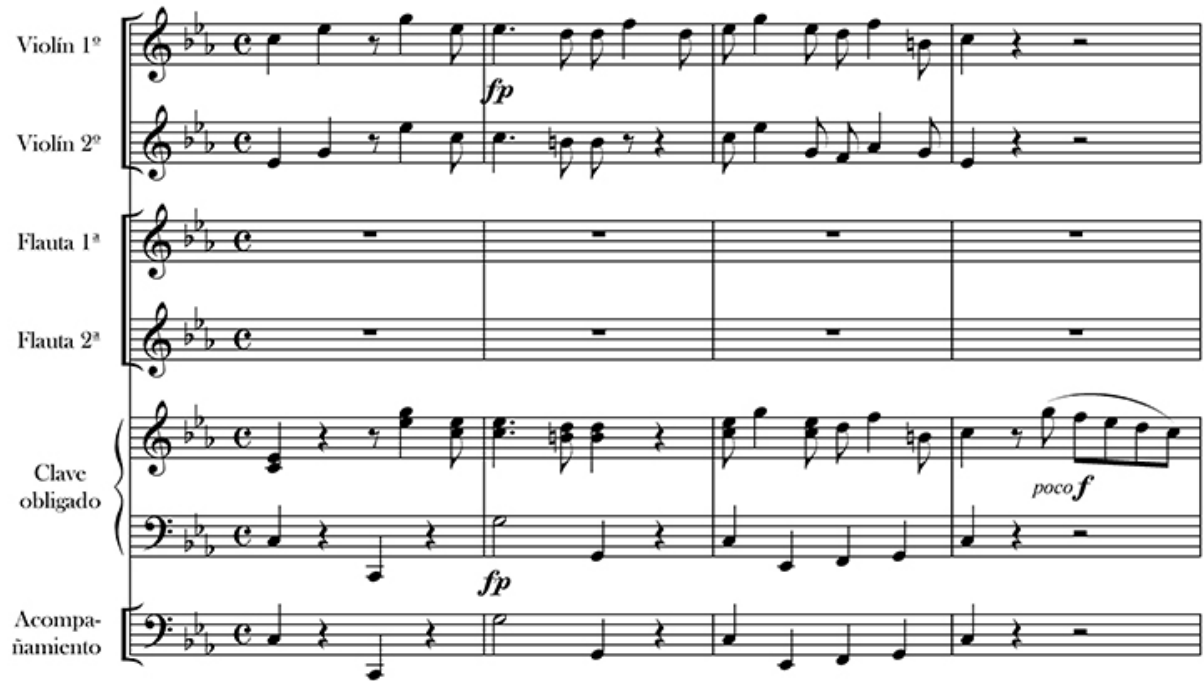

v1. 1

V. 2

5
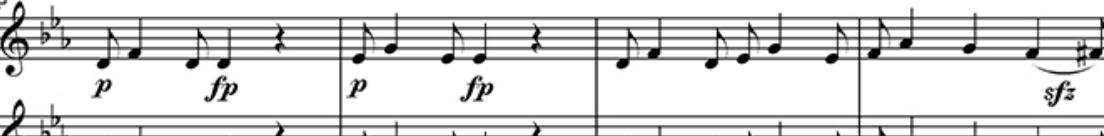

F. 1

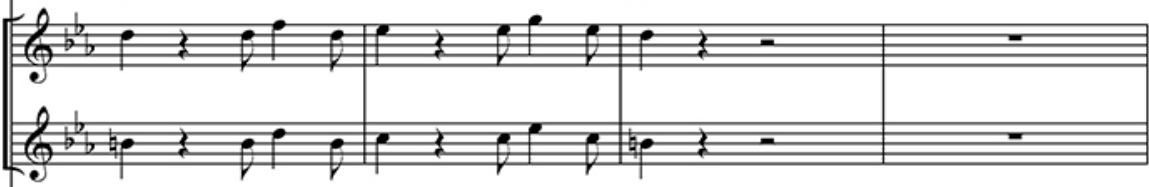

F1. 2

Clv.

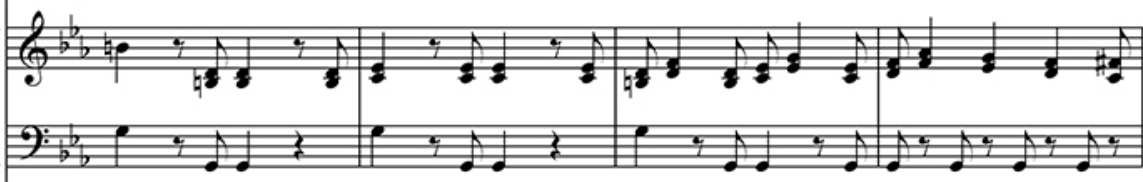

Ac.

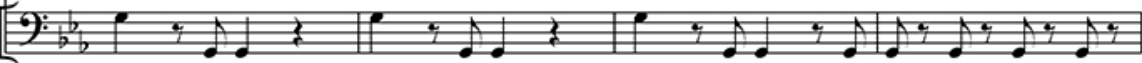


Se sienta y descansa
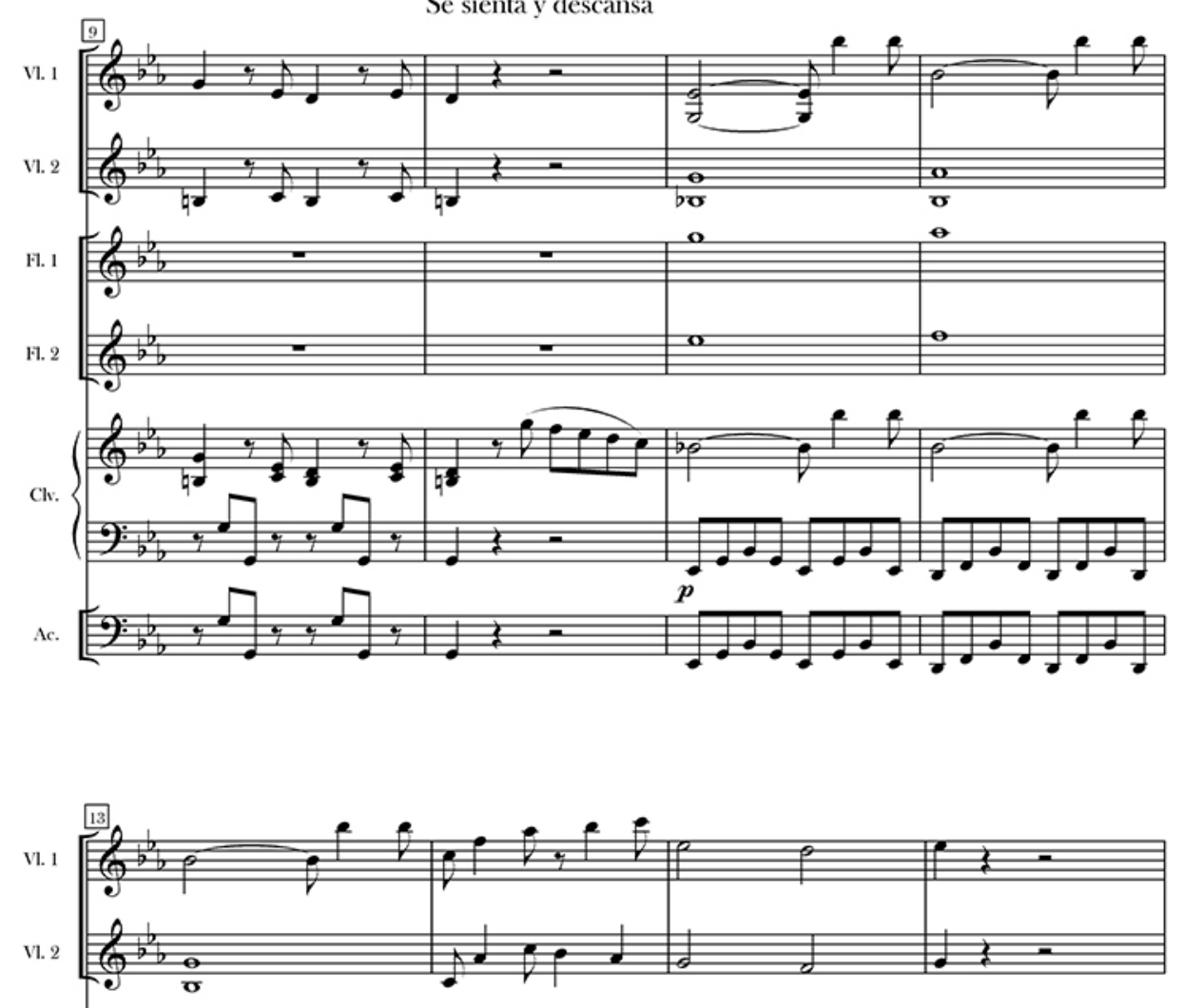

F. 1

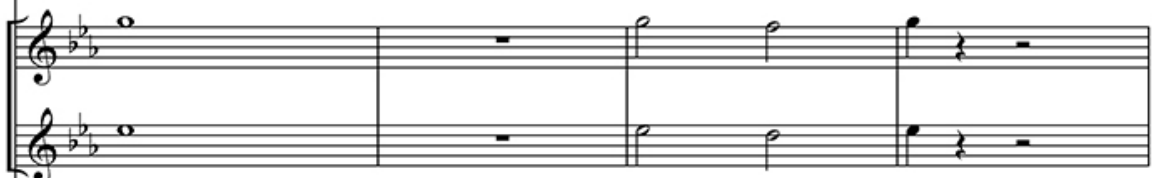

F. 2

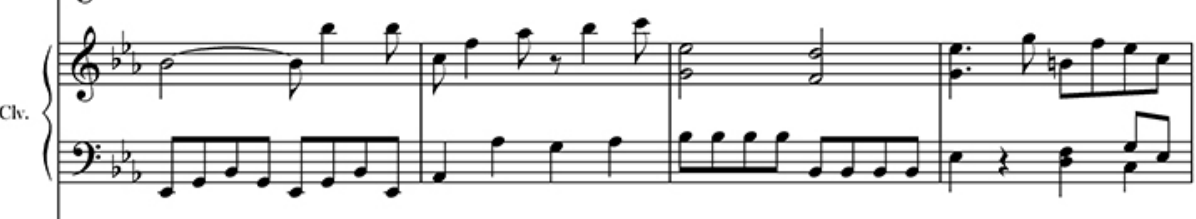

Ac.

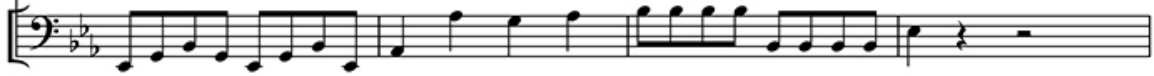


Después de tomar un poco de aliento etc.
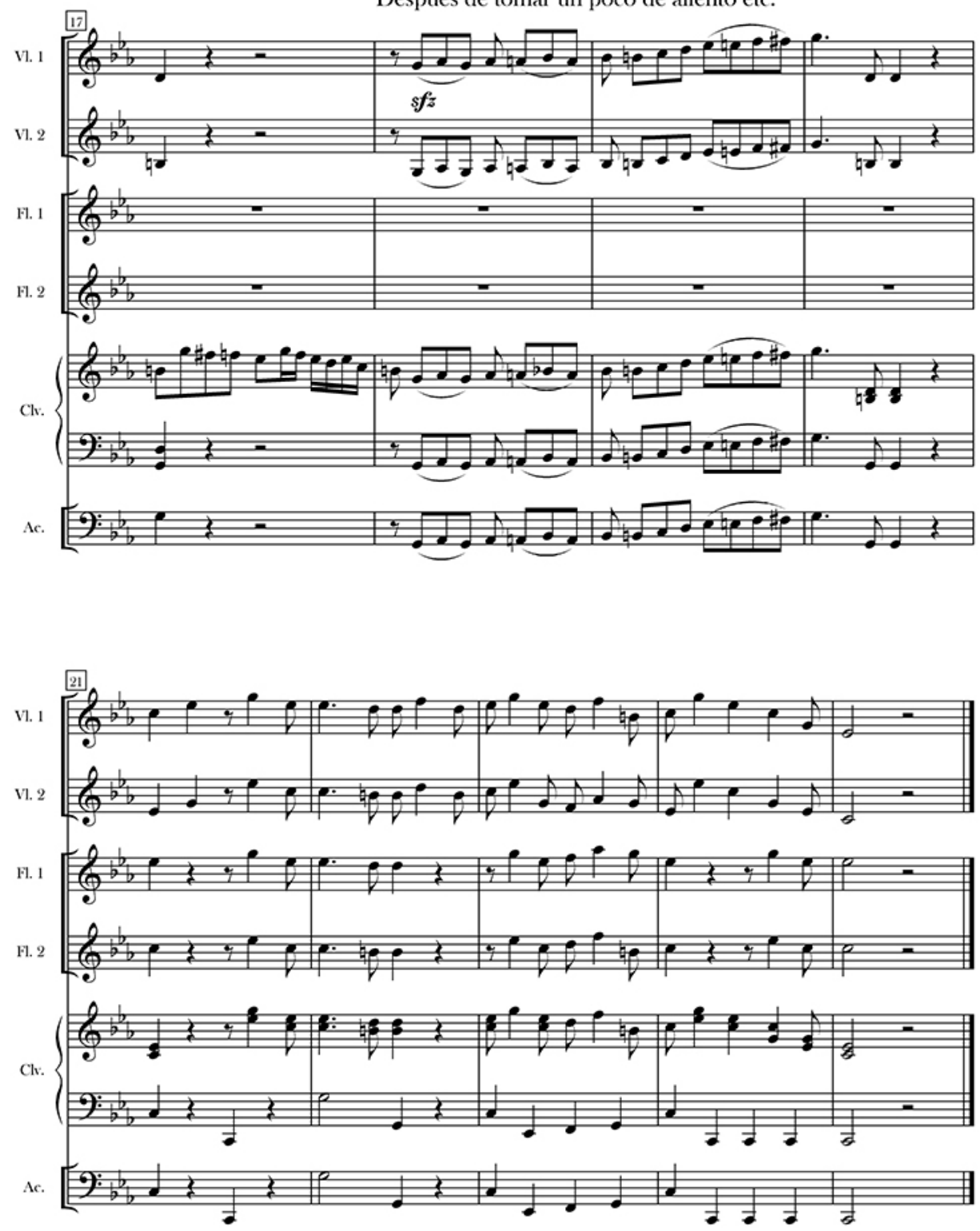

Representa 


\section{VI}

Jacobo cierra la puerta prontamente

Catul va tras de él Allegro

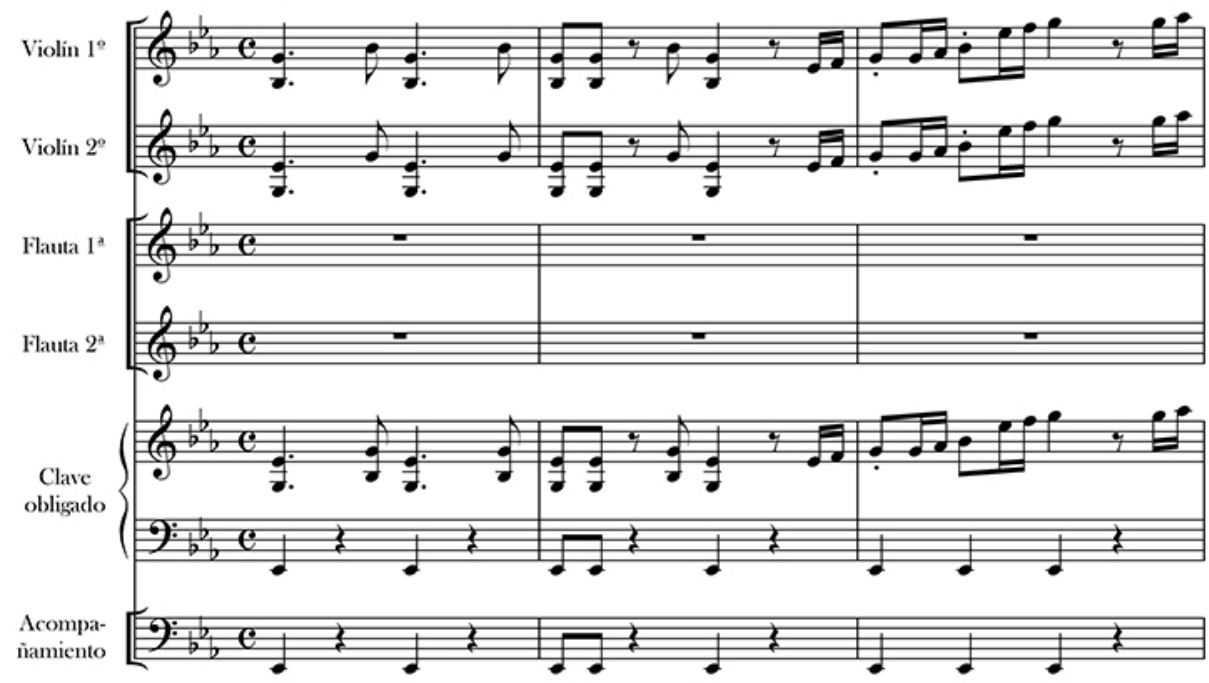

Desmayo de Catul al llegar a la puerta

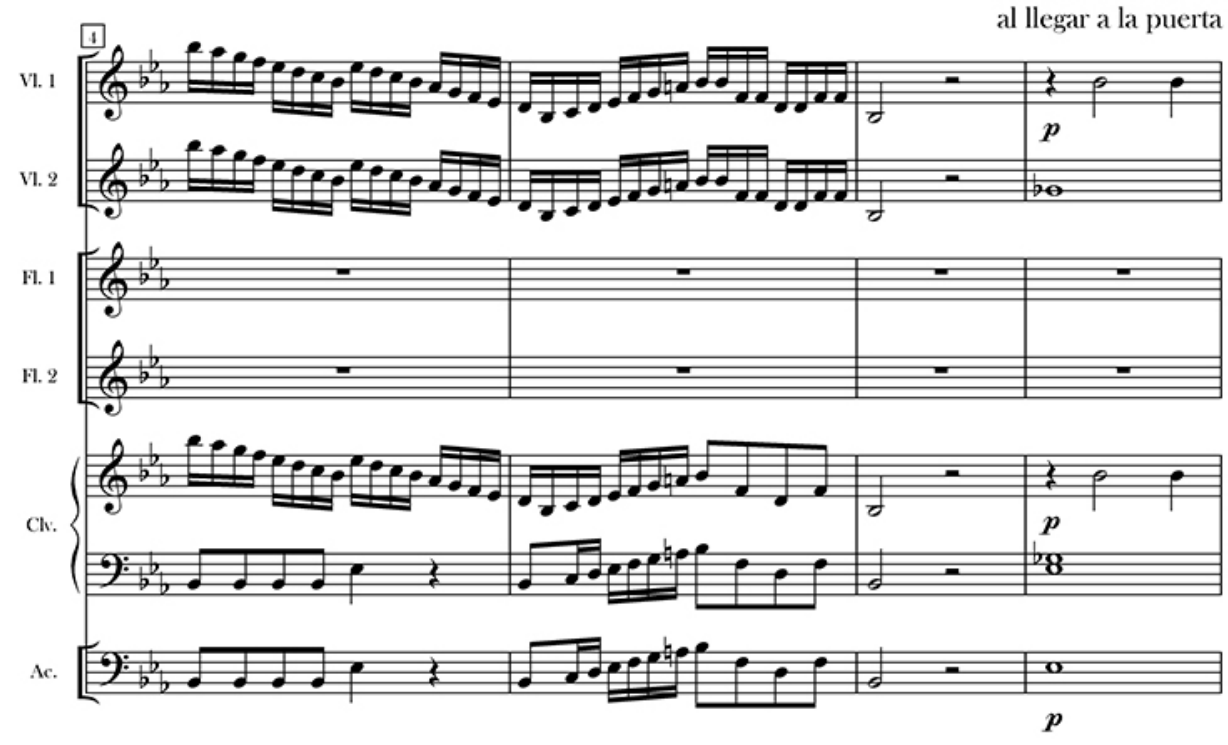




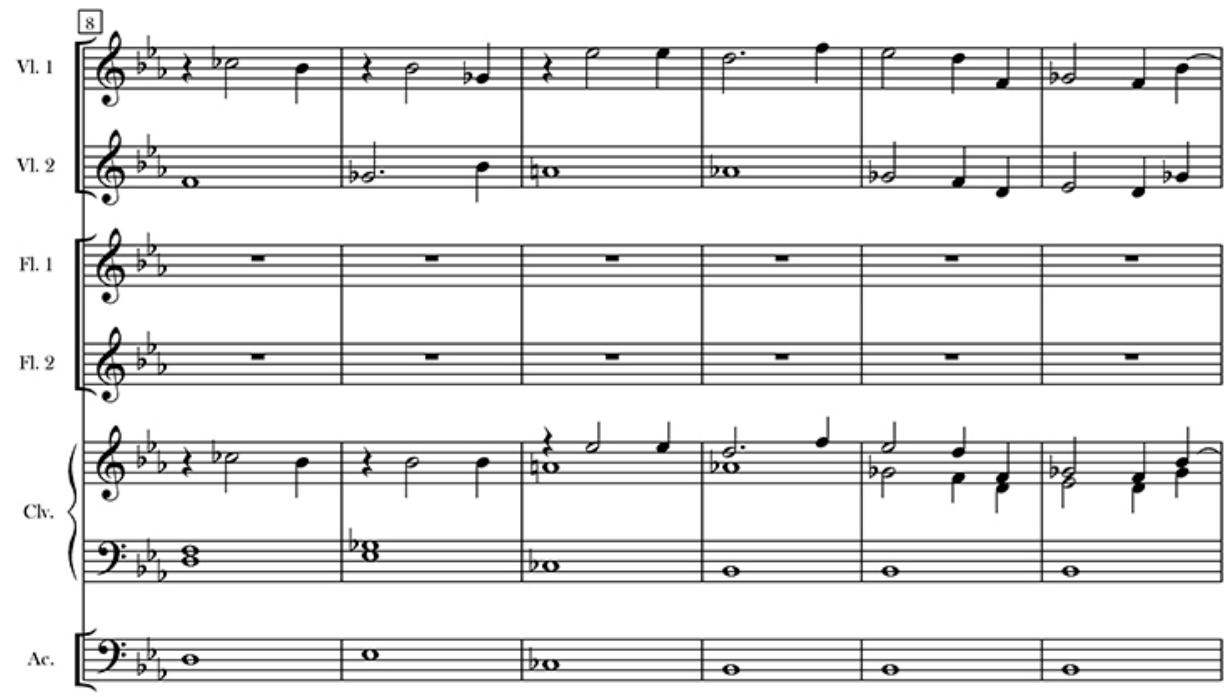

Salida de Doña

Martina, Juanito etc.

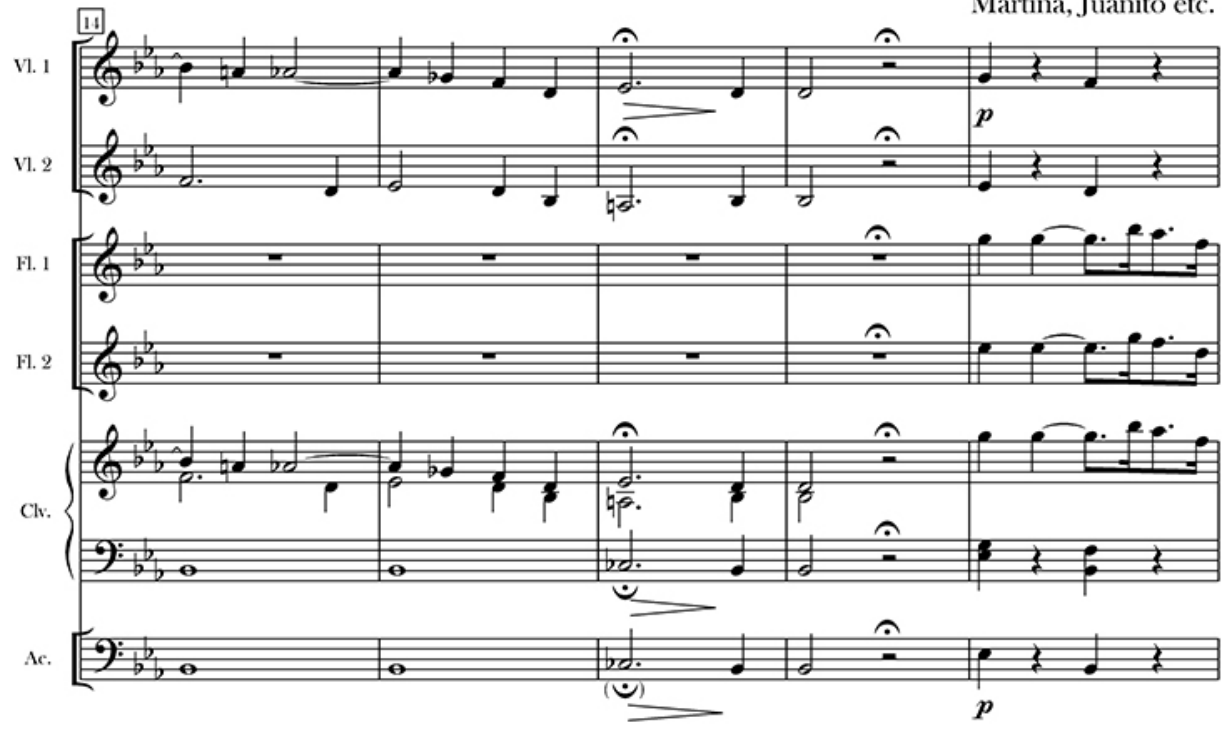



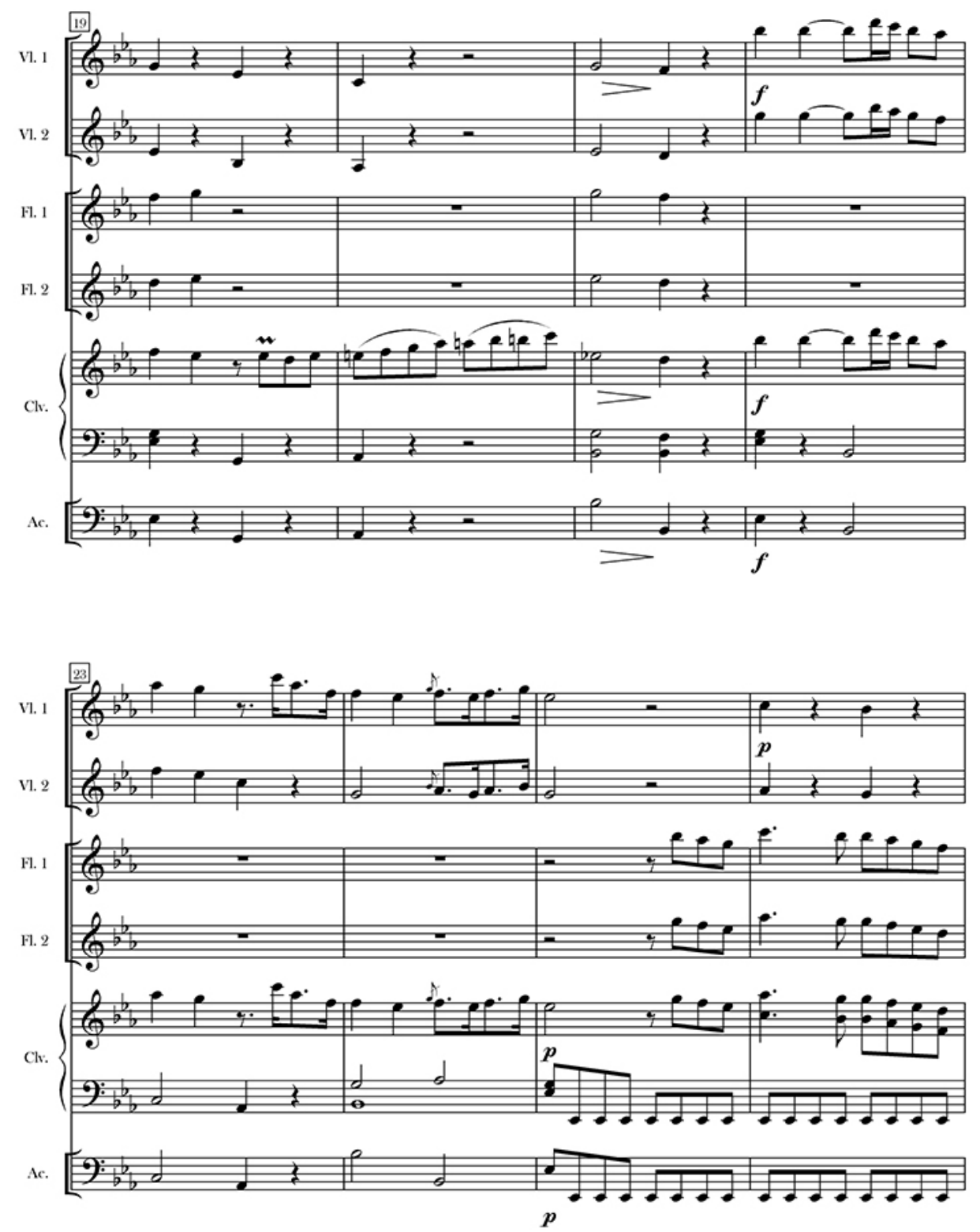

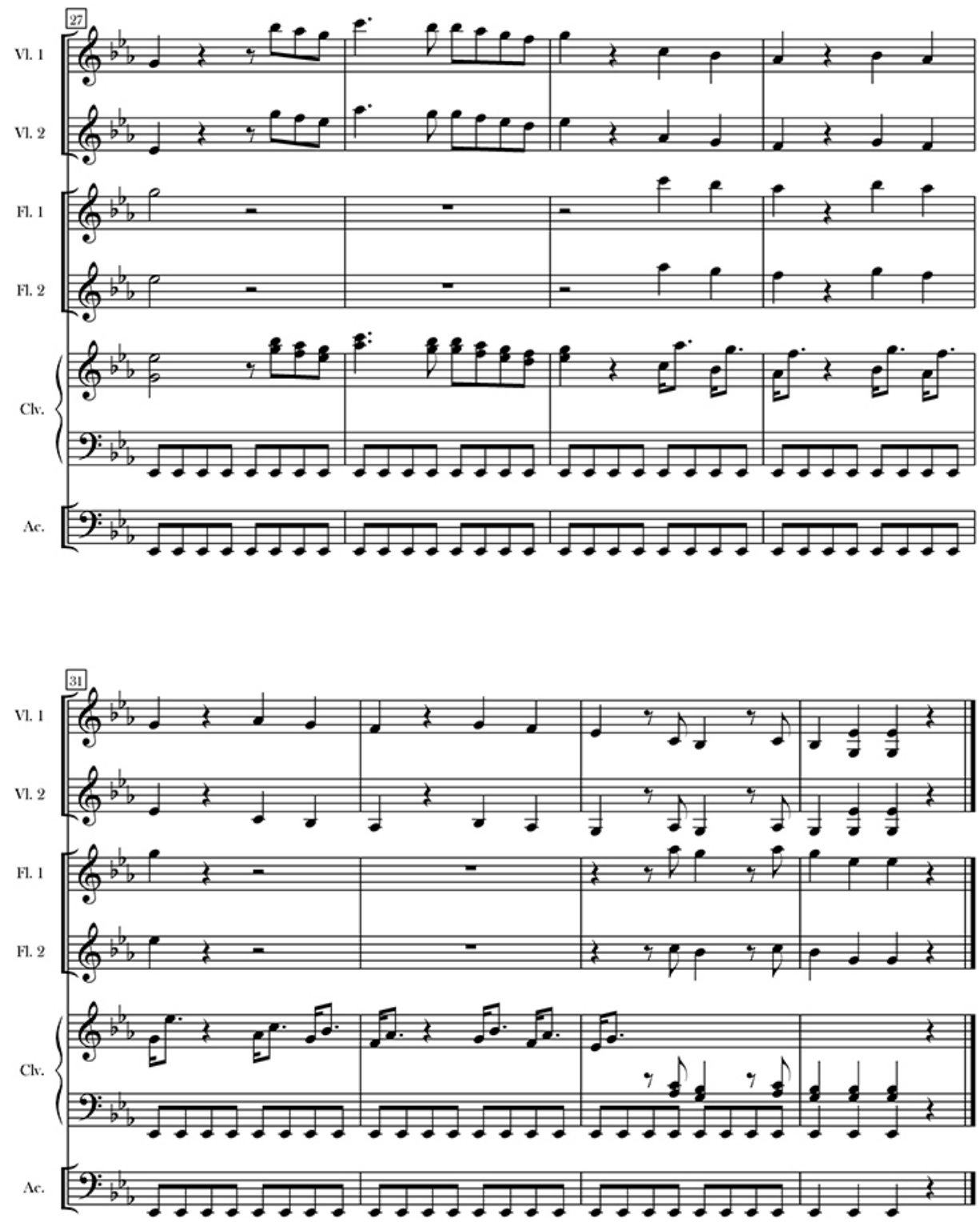
Catul se queda muy pensativo Largo siempre piano

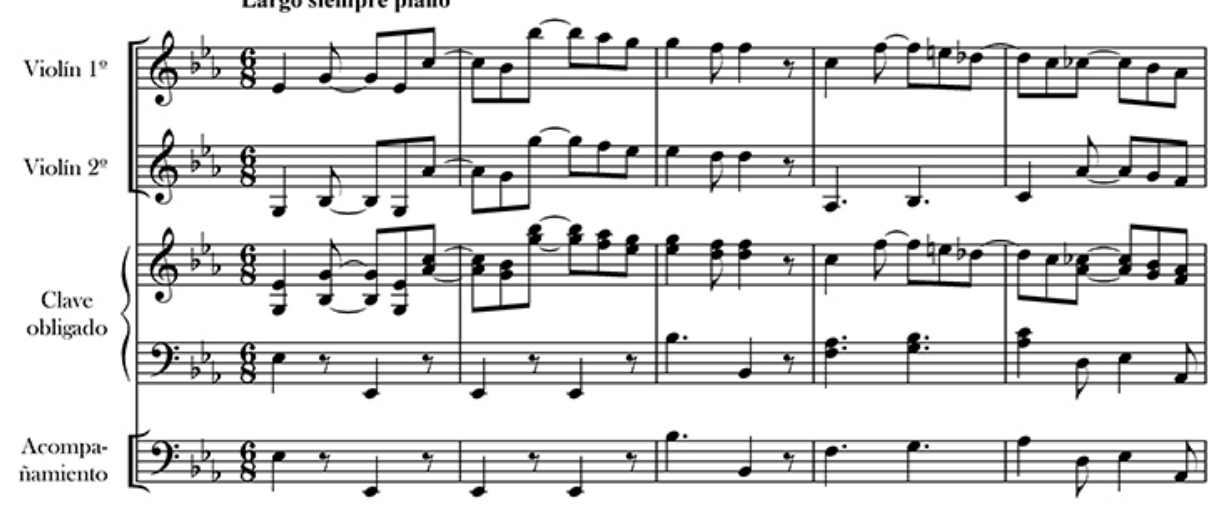

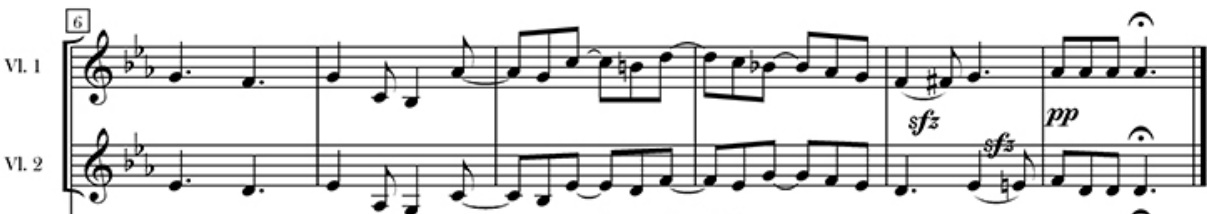

Clv.

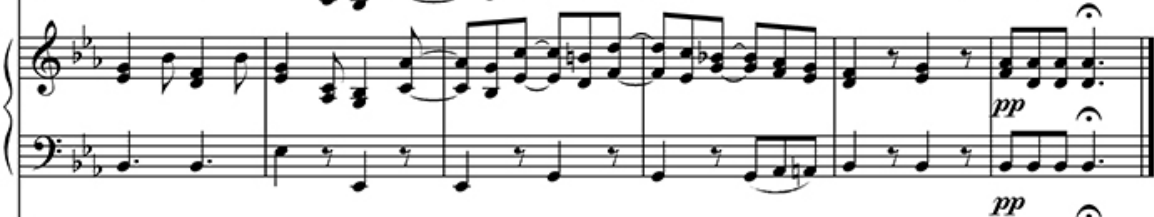

Ac.

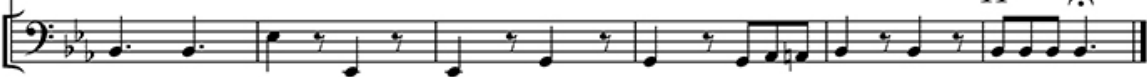




\section{VIII}

El negrito trae de la mano a Doña Martina Andante

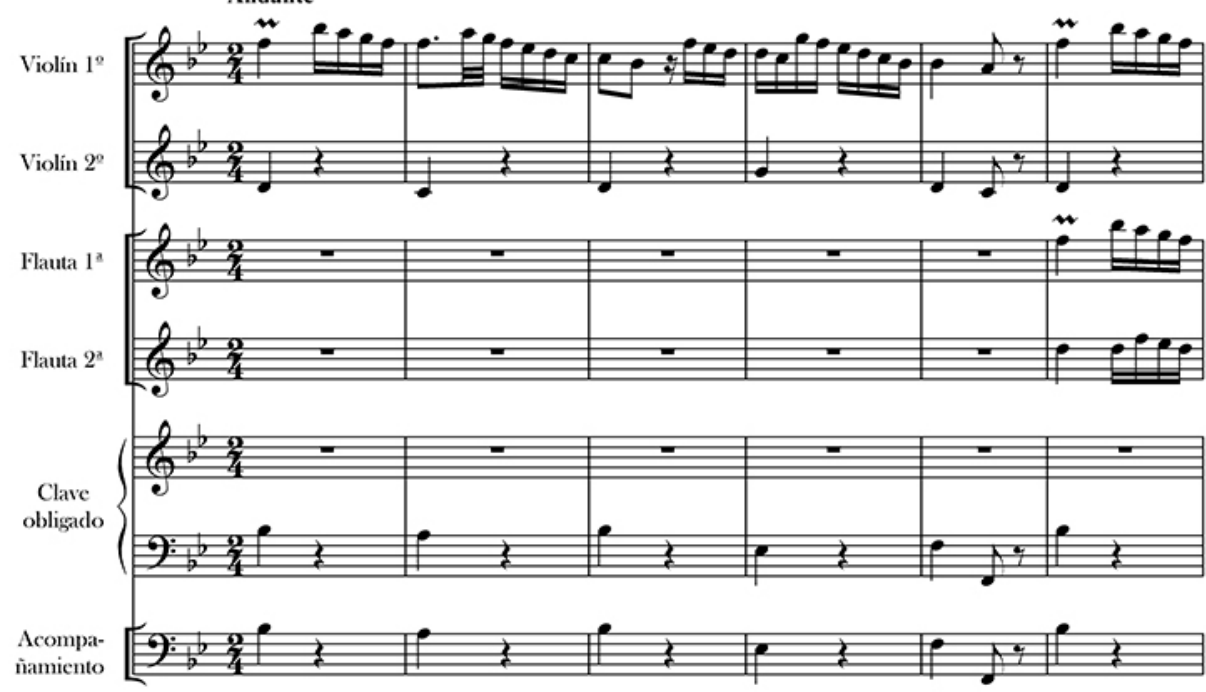

Ia lleva a la choza

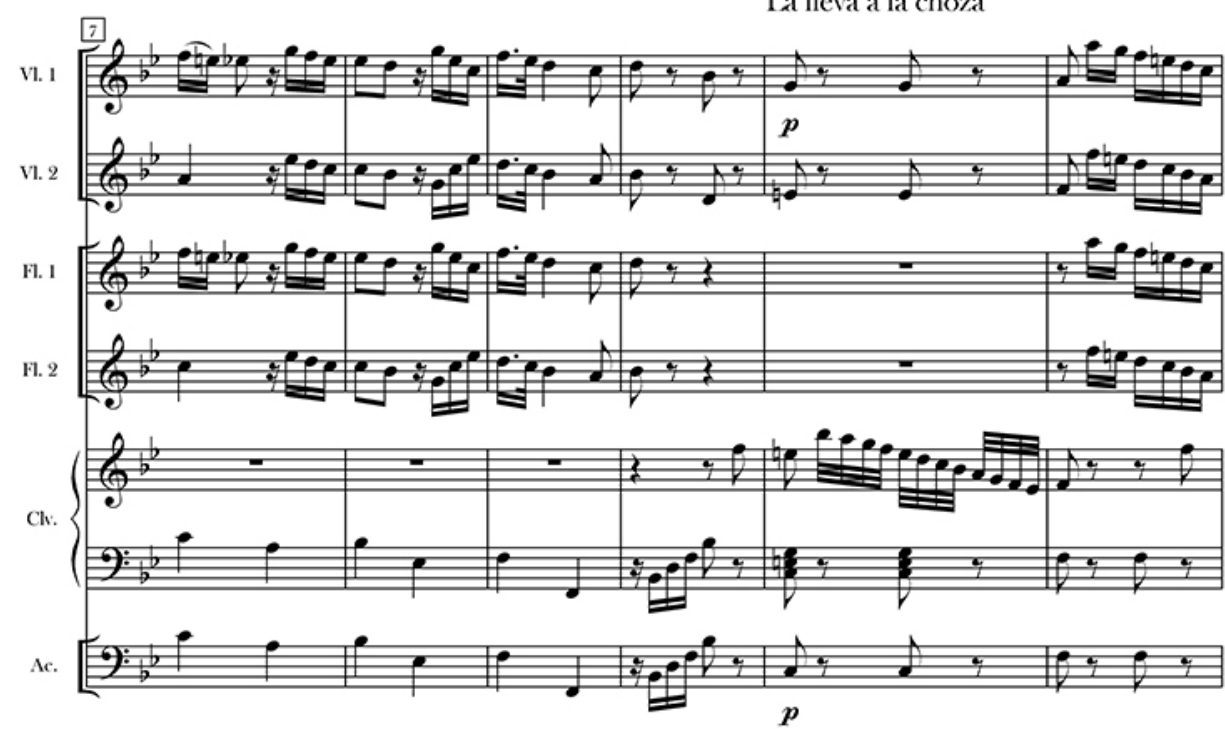



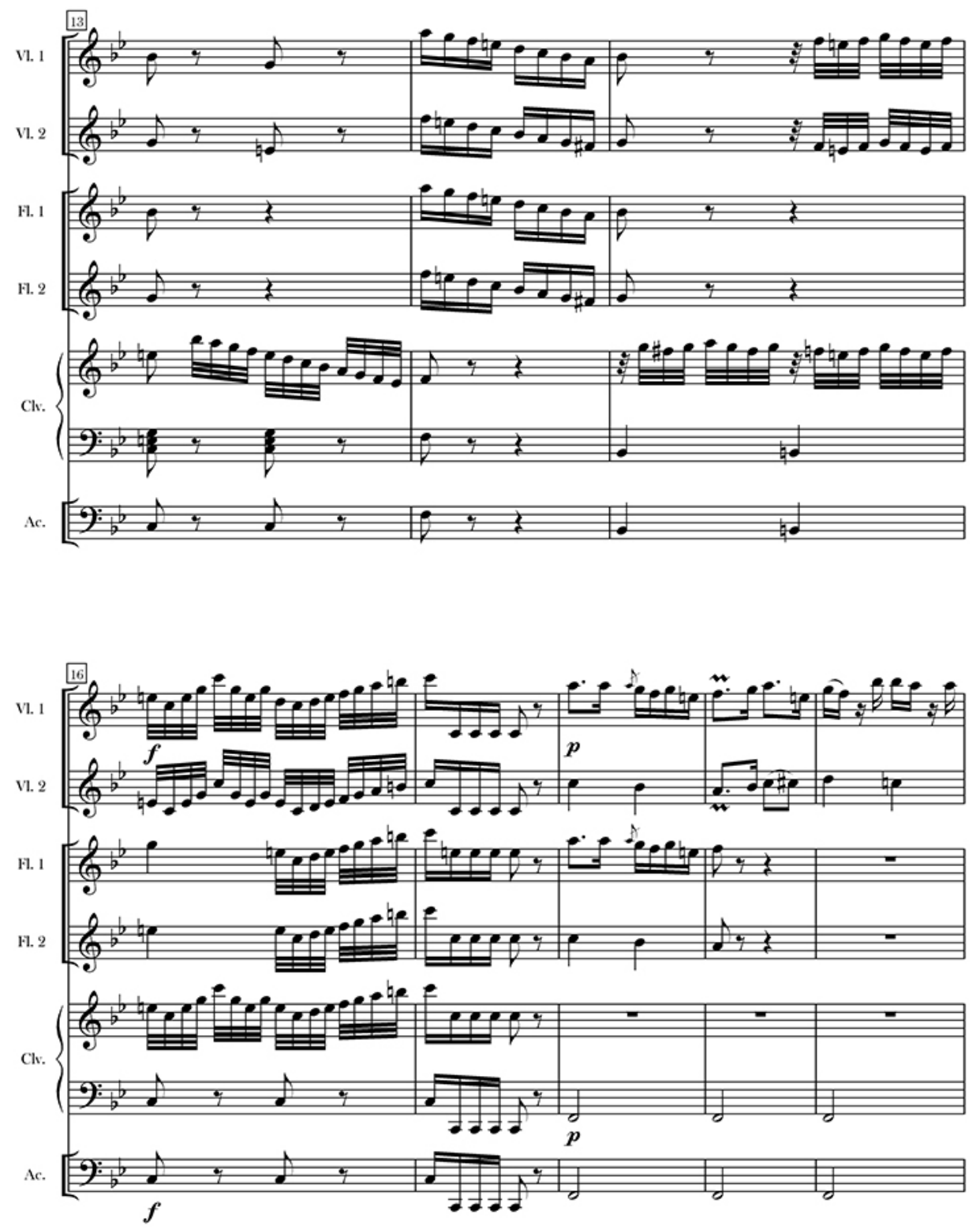
Después hacia el ingenio
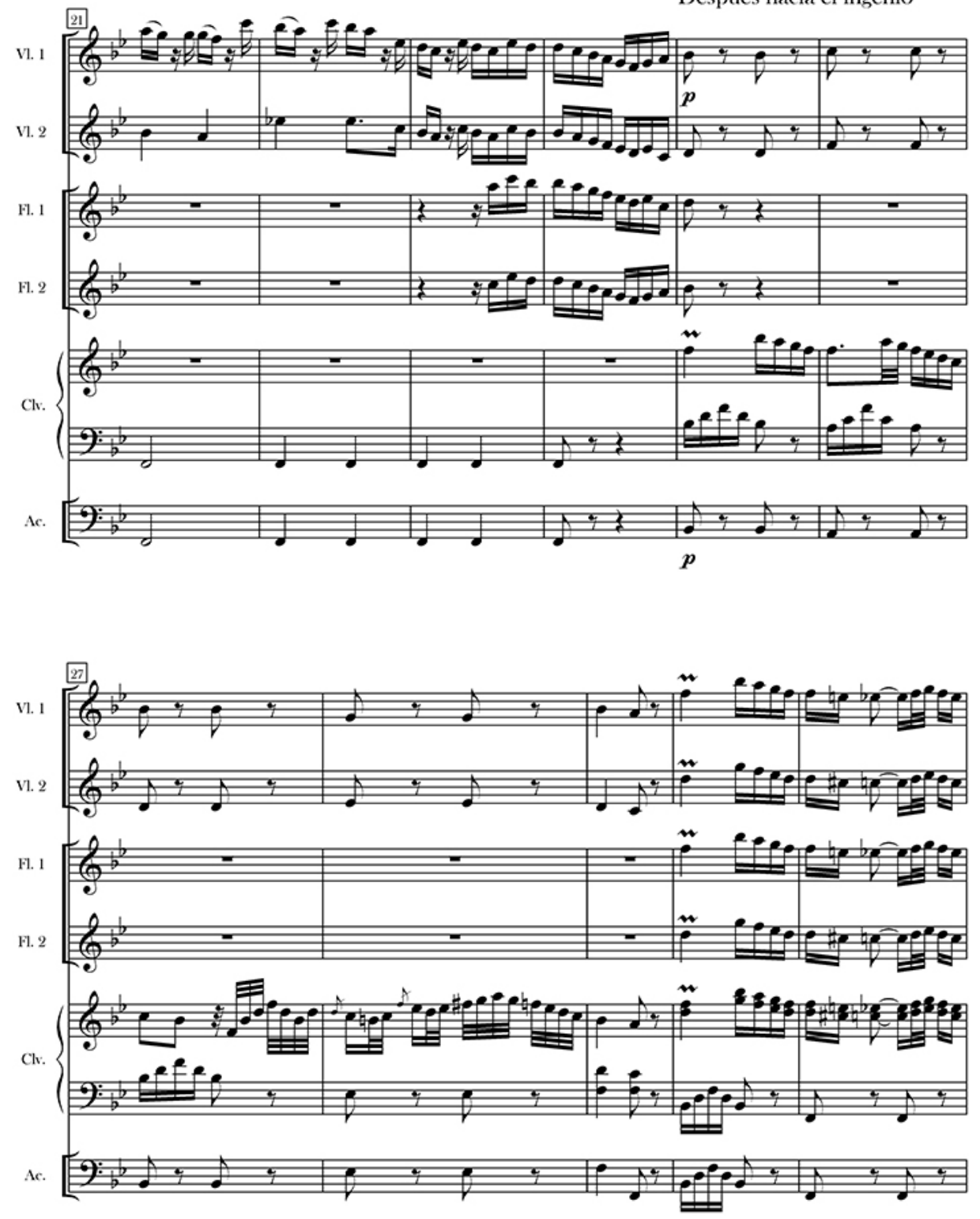
Lloro del negrito porque no encuentra a su padre
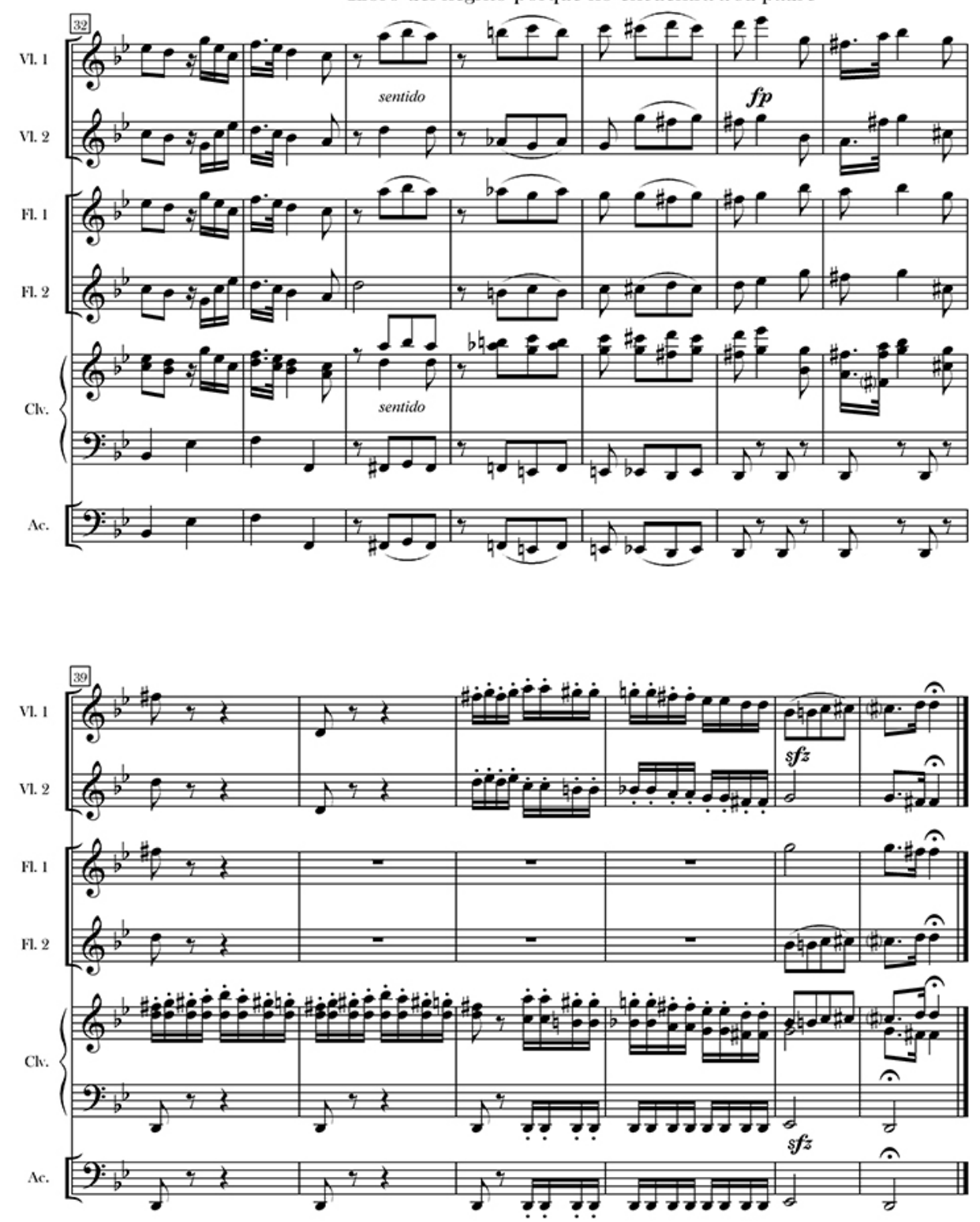